\title{
Exchange Rate Misalignment and External Imbalances: What is the Optimal Monetary Policy Response?
}

\author{
Giancarlo Corsetti \\ Cambridge University and CEPR \\ Luca Dedola \\ European Central Bank and CEPR \\ Sylvain Leduc \\ Federal Reserve Bank of San Francisco \\ February 2020 \\ Working Paper 2020-04 \\ https://www.frbsf.org/economic-research/publications/working-papers/2020/04/
}

\section{Suggested citation:}

Corsetti, Giancarlo, Luca Dedola, Sylvain Leduc. 2020. "Exchange Rate Misalignment and External Imbalances: What is the Optimal Monetary Policy Response?” Federal Reserve Bank of San Francisco Working Paper 2020-04.

The views in this paper are solely the responsibility of the authors and should not be interpreted as reflecting the views of the Federal Reserve Bank of San Francisco or the Board of Governors of the Federal Reserve System. 


\title{
Exchange Rate Misalignment and External Imbalances: What is the Optimal Monetary Policy Response?
}

\author{
Giancarlo Corsetti \\ Luca Dedola \\ Cambridge University and CEPR European Central Bank and CEPR \\ Sylvain Leduc \\ Federal Reserve Bank of San Francisco
}

This version: January 2020*

\begin{abstract}
How should monetary policy respond to capital inflows that appreciate the currency, widen the current account deficit and cause domestic overheating? Using the workhorse open-macro monetary model, we derive a quadratic approximation of the utility-based global loss function in incomplete market economies, solve for the optimal targeting rules under cooperation and characterize the constrained-optimal allocation. The answer is sharp: the optimal monetary stance is contractionary if the exchange rate pass-through (ERPT) on import prices is incomplete, expansionary if ERPT is complete - implying that misalignment and exchange rate volatility are higher in economies where incomplete pass through contains the effects of exchange rates on price competitiveness.

Keywords: Currency misalignments, trade imbalances, asset markets and risk sharing, optimal targeting rules, international policy cooperation, exchange rate pass-through JEL codes: E44, E52, E61, F41, F42
\end{abstract}

\footnotetext{
${ }^{*}$ We thank for comments, without implicating, our discussants Gianluca Benigno, Rodrigo Caputo, Harris Dellas, Charles Engel, Jordi Galì, Paolo Pesenti, Bruce Preston, Assaf Razin, Alan Sutherland, Cedric Tille, the participants at the CEPR ESSIM, the Bank of Canada-ECB Workshop on Exchange Rates, the 2019 Bank of Japan-IMES annual conference, the International Research Forum on Monetary Policy, the 2018 International Mini Conference in Notre Dame, the World Congress of the Econometric Society, the SNB conference on Monetary Policy Advances, the Barcelona Summer Forum: International Capital Flows, and seminar participants at the Banco de Chile, Bank of England, Bank of Spain, Berkeley, Bocconi University, European Central Bank, the 2017 ECB Cluster 2 Meeting in Madrid, HEC Montreal, International Monetary Fund, National University of Singapore, Oxford, Rennes and Riksbank. A previous version of this paper was circulated with the title "Exchange Rate Misalignment, Capital Flows, and Optimal Monetary Policy Trade-offs". We thank Emile Marin and Simon Lloyd for superb research assistance. Giancarlo Corsetti acknowledges the generous support of the Duisenberg Fellowship at the European Central Bank, the Keynes Fellowship at Cambridge University, and the CambridgeINET Institute at Cambridge. The views expressed in this paper are our own, and do not reflect those of the European Central Bank or its Executive Board, the Federal Reserve System, or any institution with which we are affiliated.
} 


\section{Introduction}

Cross-border capital flows raise widespread concerns about their potential adverse effects on domestic economies. Because of their impact on the exchange rate, domestic demand, and current account imbalances, inflows and outflows of capital may give rise to challenging policy trade-offs between internal objectives (inflation and output gap) and external objectives (competitiveness and trade). The debate on the most appropriate tools for managing capital movements and their macroeconomic impact has led to a reconsideration of the role of monetary policy not just as a complement to other policy instruments (ranging from macroprudential policy to capital controls) but also as a first-line defense in the absence of other readily implementable tools.

How should a central bank react, if at all, to capital inflows that deteriorate the current account imbalance and appreciate the currency? One leading answer is that the natural rate still provides a reliable compass for monetary policy: to the extent that an external deficit raises the natural rate of interest, capital inflows should be systematically matched by a tighter monetary stance (see, e.g., Obstfeld and Rogoff 2010). ${ }^{1}$ However, this answer may not be statisfactory in the presence of financial market imperfections and nominal rigidities, whereas, as recently stressed by Farhi and Werning [2016], pecuniary and demand externalities result in capital flows and deficits that are inefficient (implying either over- or underborrowing), and exchange rates that are misaligned (i.e., either overvalued or undervalued). So, to the extent that monetary tightening exacerbates overvaluation, a contraction may not be the optimal policy response to a capital inflow. Are there situations that call for curbing exchange rate variability and misalignment, even if this comes at the cost of imperfect stabilization of inflation and output gaps?

In this paper, we provide an answer to these questions by working out an analytically transparent characterization of the optimal monetary policy under commitment and cooperation using the workhorse open economy monetary model - the two-country New Keynesian model. As a standard and tractable way to introduce inefficient capital flows, we assume that the only internationally traded asset is an noncontingent bond (as in the seminal contribution by Obstfeld and Rogoff [1995]; see also Costinot et al. [2015]). ${ }^{2}$ Our key finding is that the optimal policy response to capital flows vary systematically depending on the equilibrium response of misalignment and cross-country demand to these flows - in turn a function of a few key structural features of open economies - and the degree of exchange rate pass-through (ERPT).

Specifically, we show that, the optimal monetary policy stance in response to inefficient capital inflows associated with an overvalued currency and a demand boom depends on ERPT, i.e., on whether export prices are sticky in the currency of the producer (producer currency pricing or PCP) or in the currency of the importer (local currency pricing, or LCP). ${ }^{3}$ In economies in which incomplete ERPT (due to LCP) mutes the effects of the exchange rate overvaluation

\footnotetext{
1 "Better macro performance comes from a monetary rule that recognizes how an external deficit raises the natural real rate of interest." Obstfeld and Rogoff [2010] p. 34. See also the recent discussion by Obstfeld [2019] stressing a similar point.

${ }^{2}$ In the tradition of Obstfeld and Rogoff [1995], we capture the lack of efficient diversification in the data despite the number of seemingly available cross-border assets, by focusing on bond economies.

${ }^{3}$ We focus here on the two symmetric cases of ERPT, which have been so far center stage in the literature on the optimal design of monetary policy in open economies, see Engel [2011]. In ongoing work we analyze the key asymmetric case of dominant currency pricing (DCP) recently emphasized by Gopinath [2016], which in a two-country setting requires a separate, systematic analysis also under complete markets.
} 
on the output gap, the optimal stance is contractionary. Since with incomplete ERPT the exchange rate has limited expenditure switching effects on the composition of demand, it reduces the importance of stabilizing the exchange-rate misalignment relative to stabilizing aggregate demand and inflation. As the optimal policy focuses on the latter objectives, it exacerbates the misalignment - causing the real exchange rate to be more volatile than under a policy regime of strict CPI stability. Conversely, in economies in which ERPT is complete (PCP), the optimal stance is expansionary and leans against the overvaluation of the currency, at the cost of some overheating. In this case, the optimal policy reduces the volatility of the currency and the output gap relative to the natural rate allocation associated with a policy of strict price stability.

The direction of the optimal policy response is instead independent of ERPT in economies in which, in equilibrium, inefficient capital inflows and deficits are associated with an undervalued currency and a relatively weak domestic demand - a case that can arise when domestic and foreign goods are complements, i.e., the trade elasticity is sufficiently low. Vis-à-vis an undervalued currency and an inefficiently low domestic demand, the optimal policy response to capital inflows is invariably expansionary. In this case, as monetary policy moves in support of domestic economic activity, it actually exacerbates exchange rate misalignment and volatility for any degree of ERPT, relative to strict price stability.

In developing our analysis, we make three specific contributions to the literature. First, we provide a second-order accurate approximation of the global welfare function for the standard New Keynesian two-country model with generically incomplete markets under PCP and LCP. ${ }^{4}$ The derivation of this function does not rely on specific forms of market incompleteness (e.g., bond economies and financial autarky obtained as special cases), nor on restrictive assumptions about preferences (e.g., it is not restricted to the case of unitary trade elasticity or to having the same consumption baskets across countries).

Second, the paper derives optimal targeting rules under cooperation and commitment for both PCP and LCP economies. These rules hold for a wide range of shocks (including anticipated or unanticipated shocks to preferences, productivity, markups, etc.), but, unlike the global welfare function, are specific to bond economies. Based on these rules, we provide an analytical characterization of the macroeconomic dynamic response to inefficient flows under the optimal policy.

In addition to output gaps and inflation rates, both the welfare function and targeting rules can be written as a function of real exchange rate misalignment and relative demand misallocation, themselves a function of inefficient capital flows. Different from the case of complete markets, where misalignment and demand misallocation are proportional to each other, these distortions, combined, define a gap specific to imperfect risk sharing, which we dub "wealth gap." As a third contribution, we show that this gap is a direct synthetic measure of the distortions associated with inefficient flows and plays a key role in optimal policy design. It acts much like an endogenous "markup" shock - giving rise to meaningful trade-offs between inflation, out-

\footnotetext{
${ }^{4}$ In our analysis we abstract from the question of which export pricing strategy, PCP or LCP, is optimal from the vantage point of the firms, given the optimal policy (see recent work by Mukhin 2018). An important issue for future research is whether, in economic environments supporting the optimal choice of either PCP or LCP, the optimal stabilization rules would substantially deviate from the one we derive in this paper.
} 
put gaps, demand misallocation and misalignment; ${ }^{5}$ most crucially, the wealth gap characterizes whether inefficient capital inflow leads to a positive (negative) wealth gap and overvaluation (undervaluation). In particular, we derive thresholds for the trade elasticity at which the equilibrium link between inefficient flows and misalignment switches sign. These thresholds differ across PCP economies, where they are a function of openness, and LCP economies, where they depend both on openness and the degree of nominal rigidities (in both cases, however, the thresholds are bounded above by $1 / 2$ under home bias in consumption).

To discuss macroeconomic dynamics, we find it analytically convenient to focus on "news shocks" (anticipation of future changes in fundamentals) as these typically generate capital flows that are excessive relative to the first best. ${ }^{6}$ The news shocks may stem from political risk (i.e., capital controls; see, e.g., Acharya and Bengui [2016]), changes in the efficiency of financial intermediaries (see, e.g., Gabaix and Maggiori [2015]), changes in technology or preferences impinging on savings - without loss of generality, we focus on the latter. Notably, we show that in model specifications often adopted by the literature (see, e.g., Clarida et al. 2002 and Engel 2011), capital flows in response to news shocks are exogenous to monetary policy. We can thus bring our analysis to bear directly on a case often debated in policy circles, where monetary policy can only mitigate the effects of inefficient capital flows on domestic macroeconomic dynamics, but cannot curb their size. ${ }^{7}$

Related literature Our analysis builds on a vast body of work that, over the last two decades, has reexamined a classic question in open economy macroeconomics, concerning the trade-offs between external and internal objective (see Benigno and Benigno [2003]; Clarida, Galí and Gertler [2002]; Corsetti and Pesenti [2005]; Devereux and Engel [2003]; Engel [2011]; and Galí and Monacelli [2005], among others). ${ }^{8}$ It is nonetheless useful to emphasize two strands of this literature that help highlight our contribution.

The first is the literature epitomized by Engel [2011], who studies optimal policy under complete markets contrasting LCP and PCP in the otherwise canonical open economy New Keynesian model developed by Clarida, Galí and Gertler [2002]. A key result under LCP is that the optimal monetary policy supports an allocation with CPI-price stability and no exchange rate misalignment - which also implies no cross-country misallocation of demand-the demand gap defined in Section 3.1 below. Indeed, under the maintained assumption of complete markets, trade in financial assets ensures that real exchange rate misalignment and the demand gap are always proportional to each other -independently of whether ERPT is complete (PCP)

\footnotetext{
${ }^{5}$ Moreover, while the exogenous markup shocks typically assumed in the monetary literature create aggregate global distortions, we show that the inefficiencies from capital inflows have opposing effects on different economies, that cancel out in the aggregate. A key implication is that, under the optimal policy, the Home and Foreign monetary stance will be symmetric but with the opposite sign. This is in contrast with the optimal response to the exogenous markup shocks commonly assumed by the monetary literature, which may be symmetric across borders, in particular under LCP, even when uncorrelated across countries (see e.g. Corsetti et al 2010 page 902-904).

${ }^{6}$ See the seminal papers by Beaudry and Portier [2006] and Schmitt-Grohe and Uribe [2012].

${ }^{7}$ These results are not affected by intermediation costs associated to the accumulation of net foreign asset position. Hence, barring additional algebraic complexity, they extend to economic environments such as the one studied by Gabaix and Maggiori 2016.

${ }^{8}$ As discussed in Corsetti, Dedola, and Leduc [2010], most of the papers in the literature either assume complete markets or close to efficient capital flows because of particular restrictions on preference and technology parameters.
} 
or incomplete (LCP). ${ }^{9}$ This is where our results differ from, and complement, this literature. When markets are not complete, misalignment and demand gaps are not proportional to each other-monetary policy will not be able to close both of them simultaneously, facing trade-offs between competing internal and external objectives.

The second strand of the literature includes a small number of contributions that, like ours, provide analytical characterizations of the optimal monetary policy in two-country models with incomplete financial markets. ${ }^{10}$ Obstfeld and Rogoff [2003] and Devereux [2004] examine static frameworks without capital flows, and in which prices are set one period in advance - therefore, necessarily abstracting from the welfare implications of current account dynamics and inflation. Devereux and Sutherland [2008] study a dynamic setting similar to ours, but in which markets are effectively complete under flexible prices so that price stability also attains the first-best natural rate allocation. ${ }^{11}$ Under PCP, Benigno [2009] emphasizes deviations from price stability, in economies in which net foreign asset holdings are asymmetrical in the nonstochastic steady state. However, the focus is on economies in which deviations from both purchasing power parity (PPP) and the law of one price are assumed away, in contrast with the analysis of real exchange rate misalignment at the core of optimal policy design analyzed in our paper. Our paper is also closely related to Farhi and Werning [2016], which provides a general characterization of optimal targeting rules in economies with nominal rigidities and financial market frictions. While in their contribution these authors focus on the role of macroprudential policies when monetary policy is constrained, we focus on optimal monetary policy when macroprudential policies are not available - taking into account standard welfare costs of inflation that stem from staggered price setting. Monetary policy with incomplete financial markets is also analyzed quantitatively in recent work by Rabitsch [2012], who revisits the benefits from international cooperation, and Senay and Sutherland [2019], who study the properties of instrument rules in a incomplete markets model with a portfolio of assets including bonds and equities. ${ }^{12}$

Additionally, our study is naturally related to recent literature that emphasizes the role of pecuniary externalities under collateral constraints, financial accelerator (balance-sheet) effects and over- and underborrowing relative to the constrained-efficient allocation (see Benigno et al. [2010]; Bianchi [2011]; Bianchi and Mendoza [2010]; Brunnermeier and Sannikov [2015]; Costinot et al. [2015]; Dávila and Korinek [2018]; Jeanne and Korinek [2010]; and Lorenzoni [2008], among others). ${ }^{13}$ Devereux and Yu [2016] characterize optimal monetary policy under discretion in a small open economy with occasionally binding borrowing constraints. Relative to these papers, a distinct feature is our specific focus on monetary policy in a global equilibrium characterized by overborrowing (and obviously underborrowing in the other country) with

\footnotetext{
${ }^{9}$ The result also holds when ERPT is asymmetric across borders - the case of DCP recently emphasized by Gopinath [2016]. Casas et al. [2016] study optimal monetary policy for this case, focusing on a small open economy.

${ }^{10}$ Other contributions have looked at similar issues in a small open economy framework-see e.g. De Paoli [2009] and Fanelli [2019].

${ }^{11}$ Tille [2005] assesses the welfare impact of integrating international asset markets with nominal rigidities and a stochastic component in monetary policy.

${ }^{12}$ A number of other papers numerically solve open economy models under incomplete markets, and examine optimal policy often using ad hoc loss functions. See, for example, Kollmann [2002].

${ }^{13}$ Cavallino [2016] examines foreign exchange interventions as a second instrument (in addition to conventional interest rate policy) available to the central bank to redress inefficient capital flows in an economy with borrowing constraints similar to those of Gabaix and Maggiori [2015].
} 
respect to both the first-best and the constrained-efficient allocation. ${ }^{14}$

Finally, as regards the debate on the limits of monetary policy, our results are in line with Woodford [2009], showing that openness to foreign capital does not compromise monetary control, i.e., the ability of the central bank to pursue a desired monetary stance. Yet, as stressed by Rey [2013] and Farhi and Werning [2014], inefficient capital flows may create adverse tradeoffs across policy goals, hampering a central bank's ability to maintain the economy on an efficient path. We complement these papers in that we inspect the monetary policy trade-offs created by capital flows, and characterize the optimal monetary response.

The rest of the paper is organized as follows. The next section briefly goes over the standard two-good, two-country, New Keynesian model that we take as the framework for our analysis. Section 3 derives the global loss function, discussing each of its arguments in some detail, and characterizes the cooperative optimal targeting rules under PCP and LCP. In this section, we also analyze in detail how and why incomplete markets make a difference for monetary policy. In Section 4, we consider a baseline specification of the model that we dub the Cole and Obstfeld (CO) economy, where capital flows are exogenous to policy and independent of ERPT. We can therefore focus sharply on how the optimal monetary stance changes across LCP and PCP economies. In section 5, we go beyond the role of ERPT, and further study how the optimal monetary policy varies systematically depending on the equilibrium link between misalignment and capital flows. Section 6 concludes. The appendix derives the loss function, the targeting rules, and the different allocations shown throughout the papers, and provides proofs for the propositions and lemmas stated in the text.

\section{The model economy}

The analysis builds on the standard open economy version of the workhorse model in monetary economics (see, e.g., Clarida, Galí and Gertler [2002] and Engel [2011]), with well-known characteristics. The world economy consists of two countries of equal size, $H$ and $F$. Each country specializes in one type of tradable good, produced in a number of varieties or brands defined over a continuum of unit mass. Brands of tradable goods are indexed by $h \in[0,1]$ in the Home country and $f \in[0,1]$ in the Foreign country. Firms producing the goods are monopolistic suppliers of one brand only and use labor as the only input to production. These firms set prices either in local or producer currency units and in a staggered fashion as in Calvo [1983]. Asset markets are complete at the national level, but incomplete internationally.

In what follows, we describe our setup focusing on the Home country, with the understanding that similar expressions also characterize the Foreign economy - variables referring to Foreign firms and households are marked with an asterisk.

\footnotetext{
${ }^{14}$ Key to our results is that, in equilibrium, the natural borrowing constraints in a bond economy depend on real exchange rate misalignment. Exchange rate movements drive differences in national wealth by affecting the relative value of a country's output (and thus the natural constraint on foreign borrowing), similarly to their valuation effects on outstanding foreign assets and liabilities already stressed by the literature (see, e.g., Gourinchas and Rey 2014). Since the relative value of output (and its present discounted value) reflect misalignment when financial markets are incomplete, real exchange rate movements induce an inefficient wealth wedge across countries.
} 


\subsection{The household's problem}

\subsubsection{Preferences}

We consider a cashless economy in which the representative Home agent maximizes the expected value of her lifetime utility, where instantaneous utility $U$ is a function of a consumption index, $C$, and (negatively) of labor effort $L$, specialized as follows:

$$
U\left[C_{t}, L_{t}\right]=\zeta_{C, t} \frac{C_{t}^{1-\sigma}}{1-\sigma}-\kappa \frac{L^{1+\eta}}{1+\eta}, \quad \sigma, \eta>0
$$

whereas the model also allows for shocks to marginal utilities of consumption $\zeta_{C, t}$. Foreign agents' preferences are symmetrically defined. Households consume both domestically produced and imported goods. We define $C_{t}(h)$ as the Home agent's consumption as of time $t$ of the Home good $h$; similarly, $C_{t}(f)$ is the Home agent's consumption of the imported good $f$. We assume that each good $h$ (or $f$ ) is an an imperfect substitute for all other goods' varieties, with constant elasticity of substitution $\theta>1$ :

$$
C_{\mathrm{H}, t} \equiv\left[\int_{0}^{1} C_{t}(h)^{\frac{\theta-1}{\theta}} d h\right]^{\frac{\theta}{\theta-1}}, \quad C_{\mathrm{F}, t} \equiv\left[\int_{0}^{1} C_{t}(f)^{\frac{\theta-1}{\theta}} d f\right]^{\frac{\theta}{\theta-1}} .
$$

The full consumption basket, $C_{t}$, in each country, aggregates Home and Foreign goods according to the following standard CES function:

$$
C_{t} \equiv\left[a_{\mathrm{H}}^{1 / \phi} C_{\mathrm{H}, t}^{\frac{\phi-1}{\phi}}+a_{\mathrm{F}}^{1 / \phi} C_{\mathrm{F}, t} \frac{\phi-1}{\phi}\right]^{\frac{\phi}{\phi-1}}, \quad \phi>0,
$$

where $a_{\mathrm{H}}$ and $a_{\mathrm{F}}$ are the weights on the consumption of Home and Foreign traded goods, respectively, and $\phi$ is the constant (trade) elasticity of substitution between $C_{\mathrm{H}, t}$ and $C_{\mathrm{F}, t}$.

\subsubsection{Price indexes}

The price index of the Home goods is given by:

$$
P_{\mathrm{H}, t}=\left[\int_{0}^{1} P_{t}(h)^{1-\theta} d h\right]^{\frac{1}{1-\theta}}
$$

and the price index associated with the consumption basket, $C_{t}$, is:

$$
\mathbb{P}_{t}=\left[a_{\mathrm{H}} P_{\mathrm{H}, t}^{1-\phi}+a_{\mathrm{F}} P_{\mathrm{F}, t}^{1-\phi}\right]^{\frac{1}{1-\phi}} .
$$

Let $\mathcal{E}_{t}$ denote the Home nominal exchange rate, expressed in units of Home currency per unit of Foreign currency. The real exchange rate (RER) is customarily defined as the ratio of CPIs expressed in the same currency, i.e., $\mathcal{Q}_{t}=\frac{\mathcal{E}_{t} \mathbb{P}_{t}^{*}}{\mathbb{P}_{t}}$. The terms of trade (TOT) are instead defined as the relative price of domestic imports in terms of exports: $\mathcal{T}_{t}=\frac{P_{\mathrm{F}, t}}{\mathcal{E}_{t} P_{\mathrm{H}, t}^{*}}$ if firms set prices in local currency and $\frac{\mathcal{E}_{t} P_{\mathrm{F}, t}^{*}}{P_{\mathrm{H}, t}}$ under producer currency pricing. 


\subsubsection{Budget constraints}

Home and Foreign agents trade an international bond, $B_{\mathrm{H}}$, which pays in units of Home currency and is zero in net supply. Households derive income from working, $w_{t} L_{t}$, from domestic firms' profits, $\Pi(h)$, lump-sum transfers $T_{t}$, and from interest payments, $\left(1+i_{t}\right) B_{\mathrm{H}, t}$, where $i_{t}$ is the nominal bond's yield, paid at the beginning of period $t$ but known at time $t-1$. Households use their disposable income to consume and invest in bonds. The individual flow budget constraint for the representative agent $j$ in the Home country is therefore:

$$
P_{\mathrm{H}, t} C_{\mathrm{H}, t}+P_{\mathrm{F}, t} C_{\mathrm{F}, t}+B_{\mathrm{H}, t+1} \leq w_{t} L_{t}+\left(1+i_{t-1}\right) B_{\mathrm{H}, t}+\int_{0}^{1} \Pi(h) d h+T_{t} .
$$

The household's problem thus consists of maximizing lifetime utility, defined by (1), subject to the constraint (6).

\section{$2.2 \quad$ Firms}

Firms employ domestic labor to produce a differentiated product $h$ according to the following linear production function:

$$
Y(h)=\zeta_{Y} L(h),
$$

where $L(h)$ is the demand for labor by the producer of the good $h$ and $\zeta_{Y}$ is a technology shock common to all producers in the Home country, which follows a statistical process to be specified below.

Firms are subject to nominal rigidities à la Calvo so that, at any time $t$, they keep their price fixed with probability $\alpha$. We assume that when firms update their prices, they do so simultaneously in the Home and Foreign markets. Following the literature, we consider two models of nominal price distortions in the export markets. According to the first model, firms set prices in the currency of the destination (local) market - this is the LCP hypothesis. The maximization problem is then as follows:

$$
\operatorname{Max}_{\mathcal{P}(h), \mathcal{P}^{*}(h)} E_{t}\left\{\sum_{k=0}^{\infty} p_{b t, t+k} \alpha^{k}\left(\begin{array}{c}
{\left[\mathcal{P}_{t}(h) D_{t+k}(h)+\mathcal{E}_{t} \mathcal{P}_{t}^{*}(h) D_{t+k}^{*}(h)\right]-} \\
M C_{t+k}(h)\left[D_{t+k}(h)+D_{t+k}^{*}(h)\right]
\end{array}\right)\right\}
$$

where $p_{b t, t+k}$ is the firm's stochastic nominal discount factor between $t$ and $t+k$, and the firm's demand at Home and abroad is given by:

$$
\begin{aligned}
D_{t}(h) & =\int\left(\frac{\mathcal{P}_{t}(h)}{P_{\mathrm{H}, t}}\right)^{-\theta} C_{\mathrm{H}, t} d h \\
D_{t}^{*}(h) & =\int\left(\frac{\mathcal{P}_{t}^{*}(h)}{P_{\mathrm{H}, t}^{*}}\right)^{-\theta} C_{\mathrm{H}, t}^{*} d h
\end{aligned}
$$

In these expressions, $P_{\mathrm{H}, t}$ and $P_{\mathrm{H}, t}^{*}$ denote the price index of Home goods in the Home and Foreign countries - the latter expressed in Foreign currency.

By the first-order condition of the producer's problem, the optimal price $\mathcal{P}_{t}(h)$ in domestic 
currency charged to domestic customers is:

$$
\mathcal{P}_{t}(h)=\frac{\theta}{\theta-1} \frac{E_{t} \sum_{k=0}^{\infty} \alpha^{k} p_{b t, t+k} D_{t+k}(h) M C_{t+k}(h)}{E_{t} \sum_{k=0}^{\infty} \alpha^{k} p_{b t, t+k} D_{t+k}(h)} ;
$$

while the price (in foreign currency) charged to customers in the Foreign country is:

$$
\mathcal{P}_{t}^{*}(h)=\frac{\theta}{\theta-1} \frac{E_{t} \sum_{k=0}^{\infty} \alpha^{k} p_{b t, t+k} D_{t+k}^{*}(h) M C_{t+k}(h)}{E_{t} \sum_{k=0}^{\infty} \alpha^{k} p_{b t, t+k} \mathcal{E}_{t+k} D_{t+k}^{*}(h)} .
$$

According to the alternative model, we posit that firms set prices in the producer currency - this is the PCP hypothesis. In this case, exchange rate pass-through is complete. Given that demand elasticities are assumed to be the same across markets, in domestic currency the price charged to foreign consumers is the same as the optimal price charged at Home: the law of one price holds: $\mathcal{P}_{t}^{*}(h)=\mathcal{P}_{t}(h) / \mathcal{E}_{t}$. The optimal price is similar to $(9)$, whereas Home demand is replaced by global demand.

Since all the producers that can choose their price set it to the same value, we obtain the following equations for $P_{\mathrm{H}, t}$ and $P_{\mathrm{H}, t}^{*}$

$$
\begin{aligned}
P_{\mathrm{H}, t}^{1-\theta} & =\alpha P_{\mathrm{H}, t-1}^{1-\theta}+(1-\alpha) \mathcal{P}_{t}(h)^{1-\theta} \\
P_{\mathrm{H}, t}^{* 1-\theta} & =\alpha P_{\mathrm{H}, t-1}^{* 1-\theta}+(1-\alpha) \mathcal{P}_{t}^{*}(h)^{1-\theta}
\end{aligned}
$$

Similar relations hold for the Foreign firms.

\subsection{Asset markets and exchange rate determination}

In specifying the asset market structure, we restrict trade to one financial instrument only, a safe nominal bond. While capturing the notion that international financial markets do not provide efficient risk insurance against all shocks, intertemporal trade still implies forward-looking exchange rate determination, as a by-product of equilibrium in financial markets. Namely, by combining the Euler equations for the Home households

$$
\frac{U_{C}\left(C_{t}, \zeta_{C, t}\right)}{\mathbb{P}_{t}}=\left(1+i_{t}\right) E_{t}\left[\beta \frac{U_{C}\left(C_{t+1}, \zeta_{C, t+1}\right)}{\mathbb{P}_{t+1}}\right]
$$

and the Foreign households:

$$
\begin{aligned}
\frac{U_{C}\left(C_{t}^{*}, \zeta_{C, t}^{*}\right)}{\mathbb{P}_{t}^{*}} & =\left(1+i_{t}^{*}\right) E_{t}\left[\beta \frac{U_{C}\left(C_{t+1}^{*}, \zeta_{C, t+1}^{*}\right)}{\mathbb{P}_{t+1}^{*}}\right], \\
\frac{U_{C}\left(C_{t}^{*}, \zeta_{C, t}^{*}\right)}{\mathcal{E}_{t} \mathbb{P}_{t}^{*}} & =\left(1+i_{t}\right) E_{t}\left[\beta \frac{U_{C}\left(C_{t+1}^{*}, \zeta_{C, t+1}^{*}\right)}{\mathcal{E}_{t+1} \mathbb{P}_{t+1}^{*}}\right]
\end{aligned}
$$


efficient trade in the international bond will imply the following uncovered interest parity condition, which equates the nominal stochastic discount rates in expectations:

$$
E_{t}\left[\beta \frac{U_{C}\left(C_{t+1}, \zeta_{C, t+1}\right)}{U_{C}\left(C_{t}, \zeta_{C, t}\right)} \frac{\mathbb{P}_{t}}{\mathbb{P}_{t+1}}\right]=E_{t}\left[\beta \frac{U_{C}\left(C_{t+1}^{*}, \zeta_{C, t+1}^{*}\right)}{U_{C}\left(C_{t}^{*}, \zeta_{C, t}^{*}\right)} \frac{\mathcal{E}_{t} \mathbb{P}_{t}^{*}}{\mathcal{E}_{t+1} \mathbb{P}_{t+1}^{*}}\right]
$$

Solved forward, this equation pins down the equilibrium exchange rate.

Under complete markets, the condition (12) holds state-by-state, rather than in expectations, since agents trade in contingent assets up to the point when, at the margin, the valuation of an extra unit of money of currency is equalized across borders in all circumstances. When countries are symmetric, this implies that the relative utility value of wealth, denoted by $\mathcal{W}_{t}$,

$$
\mathcal{W}_{t} \equiv \frac{U_{C}\left(C_{t}^{*}, \zeta_{C, t}^{*}\right) \frac{1}{\mathcal{E}_{t} \mathbb{P}_{t}^{*}}}{U_{C}\left(C_{t}, \zeta_{C, t}\right) \frac{1}{\mathbb{P}_{t}}}=\frac{U_{C}\left(C_{t}^{*}, \zeta_{C, t}^{*}\right)}{U_{C}\left(C_{t}, \zeta_{C, t}\right)} \frac{1}{\mathcal{Q}_{t}}
$$

is identically equal to one (see, e.g., Gravelle and Rees [1992], Backus and Smith [1993] and Obstfeld and Rogoff [2001]). Note that the marginal utility of consumption across borders is adjusted for the respective prices of the consumption basket.

Under incomplete markets, however, the equilibrium condition (12) only holds in expectations: any shocks will induce a wedge in the (ex post) relative value of wealth across borders, so that in general $\mathcal{W}_{t} \neq 1$. As shown below, $\mathcal{W}_{t}$ defines a theoretically grounded and efficient measure of cross-border imbalances that arise due to asset markets imperfections in the policy problem - in line with the approach by Woodford [2010], who studies monetary trade-offs under financial frictions in a closed economy setting allowing for agent heterogeneity.

\subsection{Log-linearized equilibrium}

Throughout the paper, the model's equilibrium conditions and constraints will be written out in log-deviations from the non-stochastic steady state - we will assume a symmetric steady-state in which the net foreign asset position is zero and the markup distortion is eliminated with appropriate subsidies. Details on the log-linearized model equations are given in appendix.

Notation-wise, we denote steady-state values of variable with an upper bar, and write $\widehat{x}_{t}=$ $\ln x_{t} / \bar{x}$ for deviations from steady state under sticky prices. While we will study different specifications of the model - PCP vs. LCP, with either unitary or generic trade elasticity - we will not denote variables differently across them, since each specification will be discussed in a separate section or subsection. We make two exceptions to this notation convention. First, we will use the superscript $f b$ to denote variables in the unique "first-best" allocation, corresponding to the case of complete asset markets, flexible prices and no markup distortions. Second, in Sections 4 and 5, we will use the superscript na to denote variables in the "natural" (flex-price) allocation.

Before delving into the analysis, it is useful to characterize upfront the first-best allocation, against which we will define our loss functions and the optimal policy rules, and discuss two key properties of the model under incomplete markets. 


\subsubsection{The first-best allocation benchmark}

The first-best output in the Home and Foreign country, $\widehat{Y}_{H, t}^{f b}$ and $\widehat{Y}_{F, t}^{f b}$, together with the real exchange rate and the terms of trade are shown in Table 1.

\section{Table 1. The first-best allocation}

$$
\begin{aligned}
\widehat{Y}_{H, t}^{f b} & =\frac{2 a_{\mathrm{H}}\left(1-a_{\mathrm{H}}\right)(\sigma \phi-1)\left(\widehat{\mathcal{T}}_{t}^{f b}\right)-\left(1-a_{\mathrm{H}}\right)\left(\widehat{\zeta}_{C, t}-\widehat{\zeta}_{C, t}^{*}\right)+\widehat{\zeta}_{C, t}+(1+\eta) \widehat{\zeta}_{Y, t}}{\eta+\sigma} \\
\widehat{Y}_{F, t}^{f b} & =\frac{2 a_{\mathrm{H}}\left(1-a_{\mathrm{H}}\right)(\sigma \phi-1)\left(-\widehat{\mathcal{T}}_{t}^{f b}\right)+\left(1-a_{\mathrm{H}}\right)\left(\widehat{\zeta}_{C, t}-\widehat{\zeta}_{C, t}^{*}\right)+\widehat{\zeta}_{C, t}^{*}+(1+\eta) \widehat{\zeta}_{Y, t}^{*}}{\eta+\sigma} . \\
\widehat{\mathcal{Q}}_{t}^{f b} & =\left(2 a_{\mathrm{H}}-1\right) \widehat{\mathcal{T}}_{t}^{f b}=\sigma\left(\widehat{C}_{t}^{f b}-\widehat{C}_{t}^{* f b}\right) . \\
\widehat{\mathcal{T}}_{t}^{f b} & =\frac{\sigma\left(\widehat{Y}_{H, t}^{f b}-\widehat{Y}_{F, t}^{f b}\right)-\left(2 a_{\mathrm{H}}-1\right)\left(\widehat{\zeta}_{C, t}-\widehat{\zeta}_{C, t}^{*}\right)}{4\left(1-a_{\mathrm{H}}\right) a_{\mathrm{H}}(\sigma \phi-1)+1},
\end{aligned}
$$

The table highlights a key feature of the first-best allocation, that we will extensively use in our analysis. Even though households are forward looking, in equilibrium relative prices and quantities depend only on the current-period (exogenous) fundamentals, not on their expected realizations in the future - in line with the well-known results in Barro and King [1984]. ${ }^{15}$ A notable implication is that, in the first best, neither the short-term real interest rate (given by the growth rates in marginal utility), nor the long-term interest rate (equal to current consumption) depends on anticipated shocks.

The same applies to cross-border capital flows. To represent these flows in the efficient economy, with slight abuse of notation we denote by $\widehat{\mathcal{B}}_{t}^{f b}$ the "notional" real net foreign assets in the first best, simply defined as cumulated real net exports (consumption minus income). Furthermore, we scale real net foreign assets with steady-state output, so that $\widehat{\mathcal{B}}_{t}^{f b} \simeq \frac{\mathcal{B}_{t}^{f b}-\overline{\mathcal{B}}}{\bar{Y}^{f b}}$. The cross-border efficient financial flows, characterized up to first order, can then be written as:

$$
\widehat{\mathcal{B}}_{t}^{f b}-\beta^{-1} \widehat{\mathcal{B}}_{t-1}^{f b}=\left(1-a_{\mathrm{H}}\right) \sigma^{-1}\left[\left(2 a_{\mathrm{H}}(\sigma \phi-1)+1-\sigma\right) \widehat{\mathcal{T}}_{t}^{f b}-\left(\widehat{\zeta}_{C, t}-\widehat{\zeta}_{C, t}^{*}\right)\right]
$$

Only contemporaneous shocks appear on the right hand side of this expression. Thus, relative to this benchmark, any cross-border flow of capital that may respond to anticipated future changes in fundamentals (or news shocks) under incomplete markets is entirely inefficient.

\subsubsection{Two key properties of the incomplete-market model}

Under the model specification assuming trade in one noncontingent bond, a key property of the log-linearized equilibrium is that, by the uncovered interest parity condition (12), $\widehat{\mathcal{W}}_{t}$ follows a random walk:

$$
E_{t} \widehat{\mathcal{W}}_{t+1}=\widehat{\mathcal{W}}_{t}
$$

Because of incomplete risk sharing, shocks will generally result in a unit root in the relative value of wealth across borders - corresponding to a unit root in net foreign assets. A comment is in order in this respect. In the text to follow, we will carry out our analysis of the bond

\footnotetext{
${ }^{15}$ Recall that in the workhorse monetary model we use in our analysis, preferences are time separable and there is no capital accumulation (see Devereux and Engel [2007] for an analysis of the optimal monetary response to news shocks under complete markets). Introducing capital accumulation and other sources of sluggish adjustment, such has habits or adjustment costs would change the results to follow mainly quantitatively.
} 
economy allowing $\widehat{\mathcal{W}}_{t}$ (and net foreign wealth) to be not stationary. This is a choice motivated by tractability and analytical transparency, but we will return to this point in subsection 4.1.1.

Finally, we emphasize that, under our assumption that the initial steady state is symmetric with zero net foreign wealth, up to first order, the dynamic of net foreign assets (and thus $\widehat{\mathcal{W}}_{t}$ ) does not respond to the ex post returns on internationally traded bonds. In other words, real net foreign assets are always capitalized at the steady-state real interest rate $\beta^{-1}$. This feature has one important implication for optimal monetary policy. Namely, starting from a symmetric steady state with zero net foreign wealth, monetary policy cannot correct misallocations in demand and misalignment by manipulating the ex post return on outstanding bonds to affect the wealth distribution (as in, e.g., Devereux and Sutherland [2008] and Benigno [2009]). Instead, it will have to operate by affecting relative prices, output and net foreign assets accumulation.

\section{Why and how do incomplete markets affect monetary policy?}

Our main objective is to examine the monetary policy trade-offs brought about by inefficient capital flows in economies where asset markets are incomplete. In this section, we first discuss the welfare-relevant gaps shaping policy trade-offs in open economies, and reconsider how incomplete markets affects the monetary transmission to macroeconomic variables. We then derive a general quadratic policy loss function obtained from a second-order approximation of agents' utility for generic incomplete markets (i.e., without specifying the form of market incompleteness). Finally, we characterize the optimal cooperative policy under commitment, in terms of optimal targeting rules.

In an open economy, in addition to output gaps and inflation rates, both the welfare function and targeting rules can be written as a function of real exchange rate misalignment and relative demand misallocation, themselves a function of inefficient capital flows. Different from the case of complete markets, where misalignment and demand misallocation are proportional to each other, these distortions, combined, define a gap specific to imperfect risk sharing, which we dub "wealth gap" (directly related to $\mathcal{W}_{t}$ ). We will show that, as a direct synthetic measure of the distortions associated with inefficient flows, this gap plays a key role in optimal policy design, acting much like an endogenous "markup" shock-i.e., it gives rise to meaningful trade-offs between inflation, output gaps, demand misallocation and misalignment.

\subsection{Welfare-relevant gaps in an open economy}

A recurrent theme in policy debates concerns the possibility that international relative prices are misaligned and cross-border borrowing/lending is too high or too low - corresponding to either excessive or insufficient demand in different countries. Drawing on previous work of ours (Corsetti et al. [2010]), we now define gaps to account for these policy concerns, using the same logic underlying the definition of the welfare-relevant output gap.

As is customary in monetary stabilization analysis, we will write policy objectives and targeting rules in terms of welfare-relevant gaps (all denoted with a tilde), expressing relevant variables as deviations from their first-best allocation values. 


\subsubsection{Misalignment: real exchange rate gaps}

We start with three relative price gaps that may open per effect of either nominal rigidities or financial frictions, or both. To wit: exchange rates are misaligned when they deviate from the value they would take in the efficient allocation. ${ }^{16}$ Since there are different measures of international relative prices, there are different (complementary) measures of misalignment. For the relative price of consumption across countries, the welfare-relevant gap is:

$$
\widetilde{\mathcal{Q}}_{t}=\widehat{\mathcal{Q}}_{t}-\widehat{\mathcal{Q}}_{t}^{f b}
$$

Analogously, for the relative price of tradables, the terms-of-trade gap is:

$$
\widetilde{\mathcal{T}}_{t}=\widehat{\mathcal{T}}_{t}-\widehat{\mathcal{T}}_{t}^{f b}
$$

Finally, misalignment can also arise when nominal rigidities in local currency translate into crossborder deviations from the law of one price (henceforth LOOP). In this case, identical goods are inefficiently traded at different prices domestically and abroad. These price differences define another dimension of misalignment, which, measured on average for the basket of Home goods, is:

$$
\widetilde{\Delta}_{\mathrm{H}, t}=\left(\widehat{\mathcal{E}}_{t}+\widehat{P}_{\mathrm{H}, t}^{*}-\widehat{P}_{\mathrm{H}, t}\right)
$$

where $\widetilde{\Delta}_{\mathrm{H}, t}$ is equal to zero when the LOOP holds. Note that, to the extent that $P_{\mathrm{H}, t}^{*}$ and $P_{\mathrm{H}, t}$ are sticky, the law of one price is violated with any movement in the exchange rate. Specifically, domestic currency depreciation tends to increase the Home firms' receipts in Home currency from selling goods abroad, relative to the Home market: Home currency depreciation raises $\widetilde{\Delta}_{\mathrm{H}, t}$. Similar considerations apply to $\widetilde{\Delta}_{\mathrm{F}, t}$.

\subsubsection{Demand misallocation: demand and wealth gaps}

Inefficient external positions could be captured by tracing capital flows in excess of the financial flows in an efficient allocation, i.e., $\widehat{\mathcal{B}}_{t}-\widehat{\mathcal{B}}_{t}^{f b}$, a gap that opens in the presence of both nominal and real (financial) distortions. ${ }^{17}$ However, there are better and more informative measures.

A first one is the "relative demand gap," denoted by $\widetilde{\mathcal{D}}_{t}$ and defined as the cross-country difference in private (consumption) demand relative to the first best:

$$
\widetilde{\mathcal{D}}_{t}=\widetilde{C_{t}}-\widetilde{C}_{t}^{*}
$$

As stressed by Engel [2011] and Fahri and Werning [2016], this gap may open also in complete market economies, per effect of nominal distortions. An expression from the demand gap under incomplete markets can be derived by taking the difference in budget constraints (where we

\footnotetext{
${ }^{16}$ We stress that, conceptually, the first-best exchange rate is not necessarily (and in general will not be) identical to the "equilibrium exchange rate," traditionally studied by international and policy institutions, as a guide to policy-making. The efficient exchange rate is theoretically and conceptually defined, at any time horizon, in relation to a hypothetical economy in which all prices are flexible and markets are complete. In fact, our measure of misalignment (as the difference between current exchange rates and the efficient one) is constructed, in strict analogy to the notion of a welfare-relevant output gap, as the difference between current output and the efficient level of output, which does not coincide with the natural rate (i.e., the level of output with flexible prices).

${ }^{17} \mathrm{It}$ is worth stressing that this measure would be well defined also under financial autarky, whereas $\widehat{\mathcal{B}}_{t}=0$.
} 
scale real net foreign assets with steady-state output, $B_{t}=\frac{B_{\mathrm{H}, t+1}}{\mathbb{P}_{t}}$ ):

$$
\begin{gathered}
\sigma \widetilde{\mathcal{D}}_{t}=\sigma\left[-2 \beta^{-1}\left(\widetilde{\mathcal{B}}_{t}-\beta \widetilde{\mathcal{B}}_{t-1}\right)\right]+\sigma\left[\widetilde{Y}_{H, t}-\widetilde{Y}_{F, t}-2\left(1-a_{\mathrm{H}}\right) \widetilde{\mathcal{T}}_{t}\right] \\
+\left(1-a_{\mathrm{H}}\right)\left[4 a_{\mathrm{H}}\left(1-a_{\mathrm{H}}\right)(\sigma \phi-1)-1\right] \sigma^{-1}\left[\left(2 a_{\mathrm{H}}(\sigma \phi-1)+1-\sigma\right) \widetilde{\mathcal{T}}_{t}^{f b}-\left(\widehat{\zeta}_{C, t}-\widehat{\zeta}_{C, t}^{*}\right)\right],
\end{gathered}
$$

Everything else equal, capital inflows $\left(\widetilde{\mathcal{B}}_{t}<0\right)$ tend to open a positive demand gap $\left(\widetilde{\mathcal{D}}_{t}>0\right)$ but in general equilibrium the response of the demand gap to the shocks driving the capital flows will also depend on the endogenous response of the terms of trade and output gaps.

Combined with the real exchange rate gap, $\widetilde{\mathcal{Q}}_{t}, \widetilde{\mathcal{D}}_{t}$ adds up to a gap that opens only in the presence of financial frictions (whether or not there are nominal rigidities). We define this as the "wealth" gap, $\widetilde{\mathcal{W}_{t}}$ :

$$
\widetilde{\mathcal{W}}_{t}=\sigma \widetilde{\mathcal{D}}_{t}-\widetilde{\mathcal{Q}}_{t}
$$

where $\widetilde{\mathcal{W}}_{t}$ is equal to log-deviations in the relative value of wealth (13). If markets are complete, $\widetilde{\mathcal{W}}_{t}=0$ always, even when the overall allocation is not efficient because of nominal rigidities or other distortions. If markets are incomplete, instead, $\widetilde{\mathcal{W}}_{t}$ will generally not be zero, and can have either sign, with a straightforward interpretation. A positive gap $\widetilde{\mathcal{W}}_{t}>0$ means that, given the relative price of consumption, the consumption of the Home (national representative) individual is inefficiently high vis-à-vis foreign consumption. While consumption smoothing is optimal from an individual-agent perspective in response to anticipated shocks, from a global welfare perspective relative Home wealth would be too high. ${ }^{18}$ Conversely, a negative gap suggests that relative Home demand is inefficiently low given the exchange rate, and/or, for a given $\widetilde{\mathcal{D}}_{t}$, the shock causes inefficient real depreciation (relative to first best).

\subsection{The wealth gap and monetary policy trade-offs specific to incomplete markets}

The wealth gap defined in the previous subsection fully captures the implications of imperfect financial markets for the policy trade-offs faced by policy-makers in the design of optimal stabilization rules. Under complete markets, the demand gap $\widetilde{\mathcal{D}}_{t}$ and real exchange rate misalignment $\widetilde{\mathcal{Q}}_{t}$ can each be different from zero-depending on the effect of nominal rigidities or other distortions (e.g., taxes or markup shocks). Yet, as a consequence of full risk sharing, they will always remain proportional to each other: $\widetilde{\mathcal{W}}_{t}=\sigma \widetilde{\mathcal{D}}_{t}-\widetilde{\mathcal{Q}}_{t}=0$. Closing $\widetilde{\mathcal{Q}}_{t}$ will be tantamount to closing $\widetilde{\mathcal{D}}_{t}$, and vice versa. Under incomplete markets, instead, since $\widetilde{\mathcal{W}}_{t}$ will generally deviate from zero, $\widetilde{\mathcal{D}}_{t}$ and $\widetilde{\mathcal{Q}}_{t}$ are no longer proportional to each other. In general, the optimal monetary rule will not close any of these gaps completely, but will have to minimize these gaps jointly with inflation and output gaps.

The wealth gap itself confronts monetary authorities with a fundamental trade-off. A monetary easing leans against real over-appreciation $\widetilde{\mathcal{Q}}_{t}$, which per se reduces the wealth gap; however, by stimulating a domestic demand boom, it also raises $\widetilde{\mathcal{D}}_{t}$, which increases the wealth

\footnotetext{
${ }^{18}$ With incomplete markets, price movements are not efficient. An appreciation of the real exchange rate associated with a Home consumption boom is a leading example of a pecuniary externality. While fully rational from an individual perspective, agents's decisions to borrow and lend move international relative prices inefficiently. These are no longer correct indicators of relative scarcity: consumption is higher where the price of the consumption bundle is also higher; see Geanakoplos and Polemarchakis [1986].
} 
gap. In some notable cases (which we analyze in detail in Section 4), the wealth gap $\widetilde{\mathcal{W}}_{t}$ (and the associated capital flows) is exogenous to policy, so that these two effects must exactly offset each other. When this is case, monetary authorities will not be able to affect the combined inefficiencies arising from both the misallocation in demand and the real exchange rate misalignment, regardless of LCP and PCP. Monetary policy may nonetheless affect their relative size. ${ }^{19}$

When $\widetilde{\mathcal{W}}_{t}$ (and thus capital flows) depends on monetary policy, its response to a monetary expansion depends on structural features such as risk aversion $\sigma$, the trade elasticity $\phi$, the degree of openness $a_{\mathrm{H}}$ (under the maintained assumptions of home bias, $a_{\mathrm{H}} \geq 1 / 2$ ), and on nominal price rigidities $\alpha$. The following proposition states threshold values of the trade elasticity as a function of $\sigma, a_{\mathrm{H}}$ and $\alpha$, above which expansionary monetary policy always widens $\widetilde{\mathcal{W}}_{t}$, that is, the effect of an expansion on relative demand always prevails on its effect on the exchange rate. In addition, the proposition states that, while widening $\widetilde{\mathcal{W}}_{t}$, a monetary easing also decreases inefficient capital inflows. The threshold differs across PCP and LCP economies.

Proposition 1: Under the maintained assumptions of home bias $\left(a_{\mathrm{H}} \geq 1 / 2\right)$ and linear disutility of labor $(\eta=0)$, monetary easing always widens $\widetilde{\mathcal{W}}_{t}(>0)$ but decreases inefficient capital inflows $\left(\widetilde{\mathcal{B}}_{t}>0\right)$ for a trade elasticity $\phi$ above the following threshold under PCP

$$
\phi>\frac{1+\frac{2 a_{\mathrm{H}}-1}{\sigma}}{2 a_{\mathrm{H}}}>0
$$

and, for $\sigma>1, \phi \geq 1$ under $L C P$.

Proof. See the appendix.

The wealth gap has substantial implications for inflation dynamics. As discussed at length in previous work of ours (CDL 2010), given consumption, equilibrium nominal wages and thus marginal costs respond to imported inflation hence to exchange rate misalignment. Given misalignment, nominal wages increase with equilibrium consumption, in turn a function of borrowing and financial flows, hence of the wealth gap. Below we write out the Phillips Curves (four of them under LCP, collapsing into two under PCP), as a function of misalignment and wealth gaps (whereas we used the fact that, under symmetry, $\widetilde{\Delta}_{\mathrm{H}, t}=\widetilde{\Delta}_{\mathrm{F}, t}=\widetilde{\Delta}_{t}$, see Engel [2011]):

$$
\begin{gathered}
\pi_{H, t}-\beta E_{t} \pi_{H, t+1}= \\
\frac{(1-\alpha \beta)(1-\alpha)}{\alpha}\left[\begin{array}{c}
(\sigma+\eta) \widetilde{Y}_{H, t} \\
-\left(1-a_{\mathrm{H}}\right)\left[2 a_{\mathrm{H}}(\sigma \phi-1)\left(\widetilde{\mathcal{T}}_{t}+\widetilde{\Delta}_{t}\right)-\widetilde{\Delta}_{t}-\widetilde{\mathcal{W}}_{t}\right]
\end{array}\right] \\
\pi_{H, t}^{*}-\beta E_{t} \pi_{H, t+1}^{*}=\pi_{H, t}-\beta E_{t} \pi_{H, t+1}+\frac{(1-\alpha \beta)(1-\alpha)}{\alpha} \widehat{\Delta}_{t},
\end{gathered}
$$

\footnotetext{
${ }^{19}$ As shown in Section 4, monetary policy will be able to determine in a constrained-efficient way how to spread the welfare costs of macroeconomic adjustment across the different gaps, including the two components of $\widetilde{\mathcal{W}}_{t}$.
} 


$$
\begin{aligned}
& \pi_{F, t}^{*}-\beta E_{t} \pi_{F, t+1}^{*}= \\
& \frac{(1-\alpha \beta)(1-\alpha)}{\alpha}\left[\begin{array}{c}
(\sigma+\eta) \widetilde{Y}_{F, t} \\
\left(1-a_{\mathrm{H}}\right)\left[2 a_{\mathrm{H}}(\sigma \phi-1)\left(\widetilde{\mathcal{T}}_{t}+\widetilde{\Delta}_{t}\right)-\widetilde{\Delta}_{t}-\widetilde{\mathcal{W}}_{t}\right]
\end{array}\right] \\
& \pi_{F, t}-\beta E_{t} \pi_{F, t+1}=\pi_{F, t}^{*}-\beta E_{t} \pi_{F, t+1}^{*}-\frac{(1-\alpha \beta)(1-\alpha)}{\alpha} \widetilde{\Delta}_{t},
\end{aligned}
$$

By inspecting the expressions above, it is apparent that the wealth gap is isomorphic to inefficient markup shocks, typically included in the analysis of the Phillips Curves - see e.g. our previous work CDL [2010]. With incomplete markets, misalignment and imbalances naturally create a trade-off between inflation and unemployment, without the need of assuming exogenous cost-push disturbances. ${ }^{20}$

\subsection{A general (quadratic) global policy loss function}

From the model, we derive a second-order approximation of the equally weighted sum of the utility of the Home and Foreign national representative agents - written in terms of the gaps defined above, all in quadratic forms. As stated in the proposition to follow, in open economy, the policy loss functions include both "internal" objectives (inflation and output gaps), and "external" ones (relative price misalignment and the relative demand gap). Our contribution is to bring modern monetary theory to bear on these traditional categories, with a precise theory-consistent reformulation of these objectives as arguments in the loss function.

Proposition 2: Under the assumption that appropriate subsidies offset firms' markups to deliver an efficient, non-distorted steady state, the period-by-period quadratic welfare function for incomplete market economies is as follows:

$$
\begin{aligned}
& \mathcal{L}_{t}^{W}-\left(\mathcal{L}_{t}^{W}\right)^{f b} \ltimes \\
& -\frac{1}{2}\left\{\begin{array}{c}
(\sigma+\eta)\left(\widetilde{Y}_{H, t}^{2}+\widetilde{Y}_{F, t}^{2}\right)+\frac{\alpha}{(1-\alpha \beta)(1-\alpha)} \theta\left(\pi_{t}^{2}+\pi_{t}^{* 2}\right) \\
-\frac{2 a_{\mathrm{H}}\left(1-a_{\mathrm{H}}\right)}{4 a_{\mathrm{H}}\left(1-a_{\mathrm{H}}\right)(\sigma \phi-1)+1}\left[(\sigma \phi-1) \sigma\left(\widetilde{Y}_{H, t}-\widetilde{Y}_{F, t}\right)^{2}-\phi\left(\widetilde{\Delta}_{t}+\widetilde{\mathcal{W}}_{t}\right)^{2}\right]
\end{array}\right\} \\
& + \text { t.i.p., }
\end{aligned}
$$

Proof. See the appendix.

In writing the above loss, for convenience, we have substituted out the terms-of-trade misalignment using its equilibrium relation with output gaps, deviations from the law of one price, and relative demand gaps. Observe that the expression is written in terms of CPI inflation and includes deviations from the LOOP, so that it directly applies to the LCP economy. Yet, its PCP counterpart can be readily obtained by setting the LOOP deviations to zero $\left(\widetilde{\Delta}_{t}=0\right)$, and using the fact that, under the law of one price, the inflation term $\pi_{t}^{2} \equiv a_{\mathrm{H}} \pi_{H, t}^{2}+\left(1-a_{\mathrm{H}}\right) \pi_{F, t}^{2}$ and $\pi_{t}^{* 2} \equiv a_{\mathrm{H}} \pi_{F, t}^{* 2}+\left(1-a_{\mathrm{H}}\right) \pi_{H, t}^{* 2}$ reduces to $\pi_{t}^{2} \equiv \pi_{H, t}^{2}$ and $\pi_{t}^{* 2} \equiv \pi_{F, t}^{* 2}{ }^{21}$

\footnotetext{
${ }^{20}$ When markets are incomplete, the distinction between "efficient" and "inefficient" shocks usually drawn by both the closed-economy literature and the open economy literature assuming perfect risk sharing becomes less useful for the purpose of policy design. Also shocks to tastes and technology (labelled "efficient") endogenously open a wealth gap and create misalignments - and thus raise meaningful policy trade-offs between output and inflation under both LCP and PCP.

${ }^{21}$ Similarly, in related work we show that the loss-function under the case of asymmetric ERPT with DCP, stressed by Gopinath [2016], is a particular case of the above loss-function under symmetric LCP.
} 
The expression (22) encompasses the cases of financial autarky (no asset is traded internationally), international trade in one bond, as well as international trade in any number of assets, including complete markets. In this sense, the above loss function generalizes and complements the ones derived in previous work of ours (CDL [2010]) for the case of autarky and complete markets. ${ }^{22}$

\subsection{Optimal targeting rules in bond economies}

To characterize the optimal cooperative policy under commitment, we focus on economies in which the only asset traded across border is a non-contingent, nominal bond-under our assumption of zero Net Foreign Asset in steady state, the bond currency denomination is not relevant for the policy problem. The derivation of the targeting rules, while complex, is standard: we maximize the present discounted value of the sum of (22) over time, subject to the log-linearized equilibrium conditions and constraints characterizing the competitive equilibrium allocation in bond economies. In the interest of transparency and tractability, we adopt a timeless perspective (see, e.g., Woodford [2010]).

Following a common practice in international economics, we synthesize the optimal cooperative policy in terms of two targeting rules: a global rule summing up inflation and output gaps across countries, and a cross-country rule, expressed in terms of differences in gaps across countries. These are presented in the propositions 3 through 6 below.

Proposition 3: From a global perspective, the optimal targeting rule under cooperation and commitment is given by

$$
\begin{aligned}
& 0=\left(\widetilde{Y}_{H, t}-\widetilde{Y}_{H, t-1}\right)+\left(\widetilde{Y}_{F, t}-\widetilde{Y}_{F, t-1}\right)+ \\
& \theta\left[a_{\mathrm{H}} \pi_{H, t}+\left(1-a_{\mathrm{H}}\right) \pi_{F, t}+a_{\mathrm{H}} \pi_{F, t}^{*}+\left(1-a_{\mathrm{H}}\right) \pi_{H, t}^{*}\right],
\end{aligned}
$$

where in the case of a PCP economy the inflation term becomes $\pi_{H, t}+\pi_{F, t}^{*}-$ since, under PCP, world CPI and PPI inflation rates coincide.

Proof. See the appendix.

From a global perspective, the optimal cooperative monetary policy stabilizes output gaps and inflation at the global level. To the extent that world inflation is zero (in the absence of exogenous markup shocks), the sum of output gaps and consumption deviations is also zero. An important implication is that the optimal monetary stance will have the opposite sign across countries. $^{23}$

Deriving cross-country or country-specific rules involves solving a system of difference equations in the different Lagrange multipliers from the optimal policy problem, which differ across LCP and PCP economies. In the LCP case, tractable general expressions - comparable to the global rule - can be derived only under some parameter restrictions. We will thus analyze the LCP and PCP economies in turn.

\footnotetext{
${ }^{22}$ Gaps (other than output gaps and inflation) similar to the ones we use in our analysis identify policy objectives arising from heterogeneity among sectors and agents in economies distorted by financial imperfections, in addition to nominal rigidities (see, e.g., Cúrdia and Woodford [2016] for an analysis in a closed economy).

${ }^{23}$ Another implication is that we can write $\widetilde{D}_{t} \equiv \widetilde{C}_{t}-\widetilde{C}_{t}^{*}=2 \widetilde{C}_{t}$. These results also hold in the natural rate allocation.
} 


\subsubsection{Incomplete pass-through (LCP) economies}

In the LCP case, a tractable rule is derived by Engel [2011] under the assumptions that markets are complete and labor elasticity is infinite $(\eta=0)$. An important result in our paper is that, as long as $\eta=0$, it is possible to derive a tractable cross-country targeting rule also under incomplete markets. This is given by the following proposition:

Proposition 4: Under LCP, if $\eta=0$, the optimal policy under cooperation and commitment is fully characterized by the general global rule (23) and the following cross-country (difference) rule:

$$
\begin{aligned}
& 0=\theta\left(\pi_{t}-\pi_{t}^{*}\right)+\widetilde{\mathcal{D}}_{t}-\widetilde{\mathcal{D}}_{t-1} \\
& +\frac{4 a_{\mathrm{H}}\left(1-a_{\mathrm{H}}\right) \phi}{2 a_{\mathrm{H}}(\phi-1)+1} \frac{(\sigma-1)}{\sigma}\left[\left(\widetilde{\mathcal{W}}_{t}-\widetilde{\mathcal{W}}_{t-1}\right)+\left(\widetilde{\Delta}_{t}-\widetilde{\Delta}_{t-1}\right)\right]
\end{aligned}
$$

where $a_{\mathrm{H}} \pi_{H, t}+\left(1-a_{\mathrm{H}}\right) \pi_{F, t}=\pi_{t}$ and $\left(1-a_{\mathrm{H}}\right) \pi_{H, t}^{*}+a_{\mathrm{H}} \pi_{F, t}^{*}=\pi_{t}^{*}$.

Proof. See the appendix.

It is worth noting that the cross country rule under complete markets is given by the first two terms on the right hand side of (24), with the CPI inflation and consumption differentials as the only arguments. The last term in (24), in the wealth gap and deviations from the law of one price, is specific to incomplete markets economies.

An important property of LCP economies under incomplete markets (somehow missed by the literature so far) allows us to derive a simpler version of the above rule. Namely, a key result derived by Engel [2011] under complete markets is that, as long as $\eta=0$, the relative prices $\widetilde{\mathcal{T}}_{t}+\widetilde{\Delta}_{t}$ are exogenous with respect to monetary policy - for any value of $\sigma$. As stated in the following proposition, the same result also holds under incomplete markets, provided agents have log-utility, i.e., $\sigma=1$. In addition, the proposition states an additional, important result: under the same parameterization, both capital flows and the wealth gap $\widetilde{\mathcal{W}}_{t}$ are also unaffected by monetary policy. ${ }^{24}$

Proposition 5. In LCP bond economies, as long as $\eta=0$ and $\sigma=1$, relative prices $\widetilde{\mathcal{T}}_{t}+\widetilde{\Delta}_{t}$, cross-border capital flows $\left(\widetilde{\mathcal{B}}_{t}\right)$ and the wealth gap $\left(\widetilde{\mathcal{W}}_{t}\right)$ are independent of monetary policy for any value of trade elasticities $\phi$.

Proof. See Appendix.

As a corollary, focusing on the case $\sigma=1$, we can combine the global and the cross- country rule, so to rewrite the optimal (cooperative) policy in terms of two symmetric country-specific rules. $^{25}$

Corollary 1. In LCP bond economies, as long as $\eta=0, \sigma=1$, and absent exogenous markup shocks, the targeting rule for the Home economy is as follows

$$
\begin{gathered}
0=\theta \pi_{t}+1 / 2 \cdot\left[\left(\widetilde{\mathcal{W}}_{t}-\widetilde{\mathcal{W}}_{t-1}\right)+\left(\widetilde{\mathcal{Q}}_{t}-\widetilde{\mathcal{Q}}_{t-1}\right)\right] \\
=\theta \pi_{t}+\left(\widetilde{C}_{t}-\widetilde{C}_{t-1}\right) .
\end{gathered}
$$

\footnotetext{
${ }^{24}$ One may observe that the last term on the right-hand side of the optimal rule (24) drops out when $\sigma=1$ : the expression for the cross-country rule (24) is the same under both complete and incomplete markets. However, as explained in the text, it does not follow that monetary policy is the same in the two cases.

${ }^{25}$ Recall that absent exogenous markup shocks, global inflation and global output gaps are both zero under the optimal policy.
} 
Proof. Set $\sigma=1$ in (24) and combine with (23).

When markets are complete $\left(\widetilde{\mathcal{W}}_{t}=0\right)$, the above reduces to the expression derived by Engel [2011]: with perfect risk insurance, provided that shocks are "efficient" (i.e., they affect tastes and/or technology only), the optimal policy sets CPI inflation rates to zero. A zero inflation policy closes the consumption gap and eliminates real exchange rate misalignment at oncereflecting the fact that these gaps are proportional to (exogenous) relative prices $\widetilde{\mathcal{T}}_{t}+\widetilde{\Delta}_{t}$. This is not possible when markets are incomplete $\left(\widetilde{\mathcal{W}}_{t} \neq 0\right)$.

It may be worth stressing that under LCP closing the real exchange rate misalignment (i.e., setting $\widetilde{\mathcal{Q}}_{t}=0$ ) does not necessarily eliminate deviations from the law of one price - nor prevent inefficient deviations from the law of one price $\widetilde{\Delta}_{t}$ from mapping into output gap fluctuations. This is apparent from the following expression:

$$
\left(\widetilde{\mathcal{T}}_{t}+\widetilde{\Delta}_{t}\right)=\frac{\widetilde{\mathcal{Q}}_{t}-\widetilde{\Delta}_{t}}{2 a_{\mathrm{H}}-1}=\frac{\sigma\left(\widetilde{Y}_{H, t}-\widetilde{Y}_{F, t}\right)-\left(2 a_{\mathrm{H}}-1\right)\left(\widetilde{\mathcal{W}}_{t}+\widetilde{\Delta}_{t}\right)}{4 a_{\mathrm{H}}\left(1-a_{\mathrm{H}}\right)(\sigma \phi-1)+1}
$$

Because of nominal distortions in import and export pricing in local currency, the optimal constrained allocation cannot be first best, whether or not risk sharing is perfect.

\subsubsection{Complete pass-through (PCP) economies}

The analytics of the cross-country targeting rule under PCP stands in sharp contrast to the LCP case above. No parameter restriction is required to derive a compact expression for the following cross-country targeting rule in a bond economy.

Proposition 6: In the PCP bond-economy, the optimal policy under cooperation and commitment is characterized by the global rule (23) in conjunction with the following cross-country targeting rule:

$$
\begin{aligned}
0= & {\left[\left(\widetilde{Y}_{H, t}-\widetilde{Y}_{H, t-1}\right)-\left(\widetilde{Y}_{F, t}-\widetilde{Y}_{F, t-1}\right)+\theta\left(\pi_{H, t}-\pi_{F, t}^{*}\right)\right] } \\
& +\frac{4 a_{\mathrm{H}}\left(1-a_{\mathrm{H}}\right) \phi}{\sigma+\eta\left(4 a_{\mathrm{H}}\left(1-a_{\mathrm{H}}\right)(\sigma \phi-1)+1\right)} \frac{2 a_{\mathrm{H}}(\sigma \phi-1)+1-\sigma}{2 a_{\mathrm{H}}(\phi-1)+1}\left(\widetilde{\mathcal{W}}_{t}-\widetilde{\mathcal{W}}_{t-1}\right) .
\end{aligned}
$$

which holds without the need to impose parametric restrictions on $\sigma, \eta$ and $\phi$.

Proof. See the appendix.

In a bond economy, the optimal cross-country targeting rule introduces a trade-off between output gaps and inflation rates on the one hand, and the wealth gap on the other hand, which is absent under complete markets - whereas (as shown by, e.g., Engel [2011] and CDL [2010]) the cross-country targeting rule is:

$$
0=\left(\widetilde{Y}_{H, t}-\widetilde{Y}_{H, t-1}\right)-\left(\widetilde{Y}_{F, t}-\widetilde{Y}_{F, t-1}\right)+\theta\left(\pi_{H, t}-\pi_{F, t}^{*}\right)
$$

Combining once again the global and cross-country rules for bond economies, (absent exogenous markup shocks) we can write a country-specific (cooperative) rule for the Home economy:

$$
0=\left[\widetilde{Y}_{H, t}-\widetilde{Y}_{H, t-1}+\theta \pi_{H, t}\right]+\frac{2 a_{\mathrm{H}}\left(1-a_{\mathrm{H}}\right) \phi}{\sigma+\eta\left(4 a_{\mathrm{H}}\left(1-a_{\mathrm{H}}\right)(\sigma \phi-1)+1\right)} \frac{2 a_{\mathrm{H}}(\sigma \phi-1)+1-\sigma}{2 a_{\mathrm{H}}(\phi-1)+1}\left(\widetilde{\mathcal{W}}_{t}-\widetilde{\mathcal{W}}_{t-1}\right)
$$


from which we derive the following important corollary. ${ }^{26}$

Corollary 2: In the PCP bond-economy, if either markets are complete $\left(\widetilde{\mathcal{W}}_{t}=0\right)$ or $\sigma=\phi=1$, the optimal policy can be characterized by a pair of country-specific rules, which are a function of purely domestic objectives. For the Home country, such rule is:

$$
\widetilde{Y}_{H, t}-\widetilde{Y}_{H, t-1}+\theta \pi_{H, t}=0 .
$$

Proof. Set $\widetilde{\mathcal{W}}_{t}=0$ or $\sigma=\phi=1$ in (26) and combine with (23)

Each country would stabilize its own output gap and GDP-deflator inflation - a result that identifies a notable (and widely discussed) case of "isomorphism" of optimal policy in closed and open economies.

\section{Optimal trade-offs and exchange rate pass-through}

In this and the next section, we bring our analysis to bear on the optimal conduct of monetary policy in economies that experience inefficient capital flows and study the macroeconomic dynamics that result from the implementation of the optimal targeting rules, contrasting LCP and PCP. We find it convenient to present our results in two steps. First, in this section, we specify a bond economy with log-consumption utility $(\sigma=1)$ and linear disutility of labor $(\eta=0)$ - two restrictions motivated by tractability in the case of LCP - as well as a unitary trade elasticity $(\phi=1)$. Because of the latter assumption, we dub this model specification "Cole and Obstfeld" or CO economy, after Cole and Obstfeld [1991]. In the CO economy, capital flows are exogenous to monetary policy and independent of the specification of nominal rigidities in export pricing (LCP or PCP). This allows us to flesh out how optimal policy changes with ERPT, holding constant the size of the inflows. As a second step, in Section 5, we extend the analysis going beyond the role of ERPT, and analyze how optimal monetary policy is shaped by the equilibrium link between capital flows and misalignment.

For the sake of analytical clarity, we will focus the analysis on shocks in the form of "news". In the first-best allocation the current values of macro variables do not respond at all to news foreshadowing changes in fundamentals in the future: the response of "gaps" (in anticipation of future changes in technology and preferences) thus coincides with the response in the equilibrium allocation until the anticipated shock materializes - with obvious gains in tractability and analytical transparency. An additional benefit, emphasized by Devereux and Engel [2007], is that the analysis of "news shocks" highlights the forward-looking nature of exchange rate determination.

\footnotetext{
${ }^{26}$ For comparison, the cross-country rule under financial autarky (derived in Corsetti et al. [2010]) is as follows:

$0=\left[\sigma+\eta\left(4 a_{\mathrm{H}}\left(1-a_{\mathrm{H}}\right)(\sigma \phi-1)+1\right)\right]\left\{\left[\widetilde{Y}_{H, t}-\widetilde{Y}_{H, t-1}\right]-\left[\widetilde{Y}_{F, t}-\widetilde{Y}_{F, t-1}\right]+\theta\left(\pi_{H, t}-\pi_{F, t}^{*}\right)\right\}+$ $4 a_{\mathrm{H}}\left(1-a_{\mathrm{H}}\right) \phi \frac{2 a_{\mathrm{H}}(\sigma \phi-1)+1-\sigma}{2 a_{\mathrm{H}}(\phi-1)+1}\left(\widehat{\mathcal{W}}_{t}-\widehat{\mathcal{W}}_{t-1}\right)+$ $2\left(1-a_{\mathrm{H}}\right)\left[2 a_{\mathrm{H}}(\sigma \phi-1) \sigma-(\sigma-1) \frac{4 a_{\mathrm{H}}\left(1-a_{\mathrm{H}}\right)(\sigma \phi-1)+1}{2 a_{\mathrm{H}}(\phi-1)+1}\right] \theta\left(\pi_{H, t}-\pi_{F, t}^{*}\right)$.
} 


\subsection{A "Cole and Obstfeld" economy with capital flows exogenous to policy}

As is well known since Cole and Obstfeld [1991] and subsequent work, in an environment with a Cobb-Douglas aggregator of domestic and imported goods $(\phi=1)$, log consumption utility $(\sigma=1)$ and symmetric home bias, production risk is efficiently shared via endogenous termsof-trade movements, regardless of whether financial markets are complete or incomplete (this applies to, e.g., productivity and markup shocks). However, full risk sharing is not granted in the presence of other sources of risk directly affecting net foreign assets, ranging from political risk (i.e., capital controls; see, e.g., Acharya and Bengui [2016]), to shocks to financial intermediation (see, e.g., Gabaix and Maggiori [2015]) and/or preference for foreign assets (see, e.g., Cavallino [2019]), as well as preference shocks impinging on savings. As many of these shocks have broadly similar analytical representations, there is little or no loss of generality in focusing on shocks to preferences that affect the intertemporal valuation of consumption, thus resulting in a motive to save and lend across borders, and generating cross-country capital flows.

\subsubsection{Financial flows in the first-best allocation and in the bond economy}

We have already shown that, in the first-best allocation, no macro variable (but the long-term interest rate) responds to news shocks. This is apparent in the CO economy, in which, imposing $\sigma=\phi=1$, our (notional) measure of efficient capital flows (14) simplifies as follows:

$$
\widehat{\mathcal{B}}_{t}^{f b}-\beta^{-1} \widehat{\mathcal{B}}_{t-1}^{f b}=-\left(1-a_{\mathrm{H}}\right)\left(\widehat{\zeta}_{C, t}-\widehat{\zeta}_{C, t}^{*}\right)
$$

In the $\mathrm{CO}$ economy, efficient inflows $\left(\widehat{\mathcal{B}}_{t}^{f b}<0\right)$ can only be driven by relative shocks to preferences in the Home country that are contemporaneous $\left.\widehat{\zeta}_{C, t}-\widehat{\zeta}_{C, t}^{*}>0\right)$. Furthermore, the assumption that $\eta=0$ implies that news shocks will have no effect on exchange rates and relative prices: ${ }^{27}$

$$
\widehat{\mathcal{Q}}_{t}^{f b}=\left(2 a_{\mathrm{H}}-1\right) \widehat{\mathcal{T}}_{t}^{f b}=0
$$

It follows that any borrowing/lending and any exchange rate movement in response to news shocks will provide a direct measure of welfare-relevant gaps.

Specifically, compare the current account in the CO economy, given by the following expression:

$$
\widehat{\mathcal{B}}_{t}=\widehat{\mathcal{B}}_{t-1}+\left(1-a_{\mathrm{H}}\right) \beta \sum_{j=0}^{\infty} \beta^{j} E_{t}\left[\left(\widehat{\zeta}_{C, t+1+j}-\widehat{\zeta}_{C, t+1+j}^{*}\right)-\left(\widehat{\zeta}_{C, t+j}-\widehat{\zeta}_{C, t+j}^{*}\right)\right],
$$

with the notional capital flows in the first best (29). An anticipated future fall in the relative degree of impatience $\left(\widehat{\zeta}_{C, t+1+j}-\widehat{\zeta}_{C, t+1+j}^{*}<0\right)$ that causes capital to flow into the Home country in the bond economy (recall that a negative $\widehat{\mathcal{B}}_{t}$ denotes inflows into the Home country), would trigger no (notional) efficient flows under perfect risk sharing. Note that the size of

\footnotetext{
${ }^{27}$ With $\sigma=\phi=1$, but $\eta>0$, Home preference shocks in favor of current consumption systematically result in a Home currency real appreciation:

$$
\widehat{\mathcal{Q}}_{t}^{f b}=-\frac{\eta}{1+\eta}\left(2 a_{\mathrm{H}}-1\right)^{2}\left(\widehat{\zeta}_{C, t}-\widehat{\zeta}_{C, t}^{*}\right)
$$
}


the inefficient borrowing and lending is increasing in openness (decreasing in home bias $a_{\mathrm{H}}$ ). Inefficient capital flows in turn open a wealth gap: ${ }^{28}$

$$
\left(1-a_{\mathrm{H}}\right) \widetilde{\mathcal{W}}_{t}=-\left(\widehat{\mathcal{B}}_{t}-\beta^{-1} \widehat{\mathcal{B}}_{t-1}\right)-\left(1-a_{\mathrm{H}}\right)\left(\widehat{\zeta}_{C, t}-\widehat{\zeta}_{C, t}^{*}\right)
$$

The expressions (30) and (31) highlight two important properties of the CO economy. First, both $\widehat{\mathcal{B}}_{t}$, and $\widetilde{\mathcal{W}}_{t}$ are a function of the exogenous preference shocks only, and therefore independent of nominal rigidities and monetary policy regimes. Second, a capital inflow $\left(\widehat{\mathcal{B}}_{t}<0\right)$ driven by news shocks will invariably lead to a positive wealth gap. As the Home economy accommodates a higher desire to save among Foreign residents, the relative Home demand $\widetilde{\mathcal{D}}_{t}$ grows excessively, and/or the real exchange rate becomes misaligned. ${ }^{29}$

Before proceeding, it is important to stress that the exogeneity of $\widehat{\mathcal{B}}_{t}$ and $\widetilde{\mathcal{W}}_{t}$ remains unaffected if cross-border flows are subject to costly intermediation in the vein of Gabaix and Maggiori [2015] — a result emphasized by Cavallino [2019]. A simple way to capture costly intermediation in our framework is to posit deviations from the uncovered interest rate parity condition that are proportional to net foreign assets:

$$
E_{t} \widetilde{\mathcal{W}}_{t+1}-\widetilde{\mathcal{W}}_{t}=-\Gamma \widehat{\mathcal{B}}_{t}
$$

With this modification, the solutions for $\widehat{\mathcal{B}}_{t}$ and $\widetilde{\mathcal{W}}_{t}$ become:

$$
\begin{gathered}
\widehat{\mathcal{B}}_{t}=\gamma_{1} \widehat{\mathcal{B}}_{t}+\left(1-a_{\mathrm{H}}\right) \sum_{j=0}^{\infty} \gamma_{2}^{-j-1} E_{t}\left[\left(\widehat{\zeta}_{C, t+1+j}-\widehat{\zeta}_{C, t+1+j}^{*}\right)-\left(\widehat{\zeta}_{C, t+j}-\widehat{\zeta}_{C, t+j}^{*}\right)\right], \\
\widetilde{\mathcal{W}}_{t}=-\left[\left(\widehat{\zeta}_{C, t}-\widehat{\zeta}_{C, t}^{*}\right)+\sum_{j=0}^{\infty} \gamma_{2}^{-j-1} E_{t}\left[\left(\widehat{\zeta}_{C, t+1+j}-\widehat{\zeta}_{C, t+1+j}^{*}\right)-\left(\widehat{\zeta}_{C, t+j}-\widehat{\zeta}_{C, t+j}^{*}\right)\right]-\frac{\gamma_{1}-\beta}{\left(1-a_{\mathrm{H}}\right) \beta} \widehat{\mathcal{B}}_{t-1}\right],
\end{gathered}
$$

where $\beta<\gamma_{1}<1<\gamma_{2} \cdot{ }^{30}$ Both $\widetilde{\mathcal{W}}_{t}$ and $\widehat{\mathcal{B}}_{t}$ are still functions of exogenous shocks only, so the

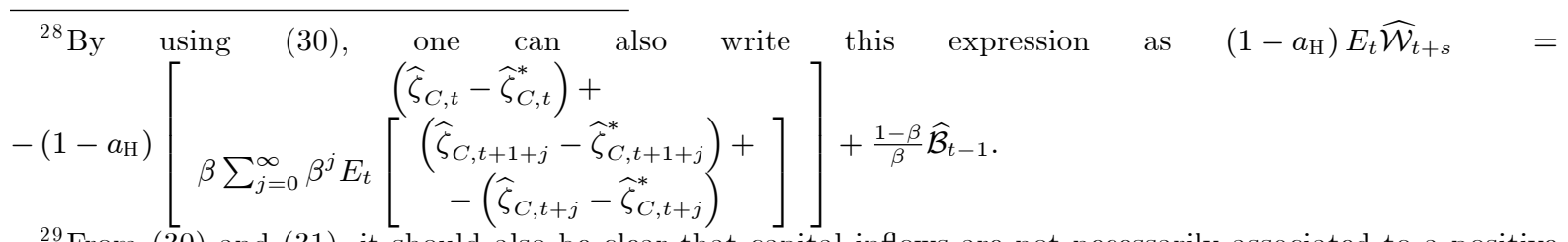

${ }^{29}$ From (30) and (31), it should also be clear that capital inflows are not necessarily associated to a positive wealth gap. Notably, both $\widehat{\mathcal{B}}_{t}$ and $\widetilde{\mathcal{W}}_{t}$ can be negative in response to contemporaneous (as opposed to "news") taste shocks, which raise the utility of current Home consumption (and associated with a relative increase in efficient output, $\left.\widehat{Y}_{H, t}^{f b}-\widehat{Y}_{F, t}^{f b}>0\right)$. In this case, although capital flows into the Home country, domestic consumption is inefficiently low relative to the foreign one. A key difference between contemporaneous and news shocks to preferences is that, with the former, $\widehat{\mathcal{B}}_{t}$ and $\widetilde{\mathcal{W}}_{t}$ have the same sign, while with the latter they have the opposite sign.

${ }^{30}$ Specifically, $\gamma_{1}$ and $\gamma_{2}$ are the roots of the characteristic equation associated with the second-order difference equation:

$$
\begin{aligned}
\widetilde{\mathcal{W}}_{t} & =\left(\frac{\widehat{\mathcal{B}}_{t-1}-\beta \widehat{\mathcal{B}}_{t}}{\left(1-a_{\mathrm{H}}\right) \beta}\right)-\left(\widehat{\zeta}_{C, t}-\widehat{\zeta}_{C, t}^{*}\right) \\
E_{t} \widetilde{\mathcal{W}}_{t+1}-\widetilde{\mathcal{W}}_{t} & =-\Gamma \widehat{\mathcal{B}}_{t},
\end{aligned}
$$

namely:

$$
\beta \gamma^{2}-(1+\beta+\beta \Gamma) \gamma+1=0 .
$$


optimal targeting rules are the same as those derived above under both LCP and PCP for the CO economy. Clearly, setting $\Gamma=0$ in the last expression leads to $\gamma_{1}=1$ and $\gamma_{2}=1 / \beta$, which yields expressions (30) and (31) above. We abstract from intermediation costs in the rest of our analysis.

\subsubsection{The natural rate allocation}

With imperfect insurance, inefficient capital flows open a wealth gap and result in misallocation independently of price stickiness. Table 2 shows the flexible price allocation for the $\mathrm{CO}$ economy - which coincides with the natural rate allocation. In this table, all variables are expressed as deviations from this allocation-defining gaps denoted with a superscript "na."

$$
\begin{aligned}
& \text { Table 2. The natural rate allocation in the CO economy } \\
& \widetilde{Y}_{H, t}^{n a}=-\widetilde{Y}_{F, t}^{n a}=-\left(1-a_{\mathrm{H}}\right) \widetilde{\mathcal{W}}_{t} \\
& \widetilde{\mathcal{T}}_{t}^{n a}=-\widetilde{\mathcal{W}}_{t} \\
& \widetilde{\mathcal{Q}}_{t}^{n a}=-\left(2 a_{\mathrm{H}}-1\right) \widetilde{\mathcal{W}}_{t} \\
& \widetilde{\mathcal{D}}_{t}^{n a}=2\left(1-a_{\mathrm{H}}\right) \widetilde{\mathcal{W}}_{t} \\
& \widetilde{C}_{t}^{n a}=-\widetilde{C}_{t}^{* n a}=\frac{1}{2} \widetilde{\mathcal{D}}_{t}^{n a}=\left(1-a_{\mathrm{H}}\right) \widetilde{\mathcal{W}}_{t}
\end{aligned}
$$

In the $\mathrm{CO}$ economy, under flexible prices, output gaps, exchange rate misalignment and the relative demand gap are all proportional to the (exogenous) gap $\widetilde{\mathcal{W}}_{t}$. When $\widetilde{\mathcal{W}}_{t}>0$ and $\widehat{\mathcal{B}}_{t}<0$, as is the case in response to news shocks, capital inflows result in a negative welfare-relevant output gap, an overvalued real exchange rate and an excessive level of domestic consumption, both in absolute terms and relative to Foreigners. The Foreign economy just mirrors the Home responses - through their effects on $\widetilde{\mathcal{W}}_{t}$, the inefficiencies in the shock transmission are purely redistributive. Note that, with $a_{\mathrm{H}}>1 / 2$, in equilibrium, adjustment to shocks requires Home real appreciation. Intuitively, the capital inflow into Home amounts to a transfer of purchasing power from abroad. Since there is home bias in demand, if relative prices did not adjust, the transfer would translate into an excess supply of Foreign goods.

In response to news shocks, as $\widetilde{\mathcal{W}}_{t}>0$, all gaps widen on impact. Afterwards, since in the linearized equilibrium $E_{t} \widetilde{\mathcal{W}}_{t+1}=\widetilde{\mathcal{W}}_{t}$, gaps remain constant. ${ }^{31}$ Note that, in the intervening period between the arrival of the news and future changes in fundamentals, the short-term natural rate of interest (equal to the growth rate of consumption under flexible prices) is not affected at all by the shocks. ${ }^{32}$

It is well understood that, in general, an allocation with price stability under PCP is the same as the natural rate allocation, but an allocation with CPI stability under LCP is not. Nonetheless, it can be shown that the expressions for consumption demand and relative demand in Table 2 hold also under CPI price stability in the LCP economy. This result will be useful in the analysis below.

\footnotetext{
${ }^{31}$ When fundamentals change in the future, of course, macroeconomic variables will change again, including both deviations $\widehat{C}_{t+s}^{n a}$ and efficient consumption $\widehat{C}_{t+s}^{f b}$, but not $\widehat{\mathcal{Q}}_{t}^{n a}$, under $\eta=0$.

${ }^{32}$ It follows that a monetary policy framework equating the policy rate to the short-term natural rate would be initially unresponsive to the capital inflows.
} 


\subsection{Domestic demand stabilization with incomplete pass-through (LCP economies)}

We now analyze the dynamics of the CO economy under the optimal policy with LCP. Below we show the constrained-efficient allocation - obtained by writing out the economy dynamics in response to a news shock when monetary authorities in each country implement the optimal targeting rule (25). The Home allocation is shown in Table 3, as a function of the (exogenous) wealth gap (31)) - the Foreign one is the symmetric counterpart.

Table 3: Constrained-efficient allocation under LCP in the CO economy

$$
\begin{aligned}
& \widetilde{Y}_{H, t}=2 a_{\mathrm{H}}\left(1-a_{\mathrm{H}}\right)\left(\widetilde{\mathcal{T}}_{t}+\widetilde{\Delta}_{t}\right)+1 / 2 \cdot\left(2 a_{\mathrm{H}}-1\right) \widetilde{\mathcal{D}}_{t} \\
& \theta \pi_{t}=-\left(1-a_{\mathrm{H}}\right) \frac{\left(\beta \varkappa_{2}-1\right)}{\beta \varkappa_{2}} \widetilde{\mathcal{W}}_{t}+\frac{1}{2}\left[\frac{\left(\beta \varkappa_{2}-1\right)}{\beta \varkappa_{2}} \widetilde{\mathcal{W}}_{t-1}+\left(1-\varkappa_{1}\right) \widetilde{\mathcal{Q}}_{t-1}\right] \\
& \widetilde{\mathcal{T}}_{t}+\widetilde{\Delta}_{t}=-\frac{\left(\beta \nu_{2}-1\right)}{\beta \nu_{2}} \widetilde{\mathcal{W}}_{t}+\nu_{1}\left(\widetilde{\mathcal{T}}_{t-1}+\widetilde{\Delta}_{t-1}\right) \\
& \widetilde{\mathcal{Q}}_{t}=-\left(2 a_{\mathrm{H}}-1\right) \frac{\left(\beta \varkappa_{2}-1\right)}{\beta \varkappa_{2}} \widetilde{\mathcal{W}}_{t}-\frac{1}{\beta \varkappa_{2}}\left(\widetilde{\mathcal{W}}_{t}-\widetilde{\mathcal{W}}_{t-1}\right)+\varkappa_{1} \widetilde{\mathcal{Q}}_{t-1} \\
& \widetilde{\mathcal{D}}_{t}=2\left(1-a_{\mathrm{H}}\right) \frac{\left(\beta \varkappa_{2}-1\right)}{\beta \varkappa_{2}} \widetilde{\mathcal{W}}_{t}+\frac{1}{\beta \varkappa_{2}} \widetilde{\mathcal{W}}_{t-1}+\varkappa_{1} \widetilde{\mathcal{Q}}_{t-1} .
\end{aligned}
$$

In the table, $\varkappa_{1}, \nu_{1}$ and $\varkappa_{2}, \nu_{2}$ denote, respectively, stable and unstable eigenvalues - where the former $\left(\nu_{1}, \varkappa_{1}\right)$ are increasing, the latter $\left(\varkappa_{2}, \nu_{2}\right)$ decreasing in the degree of price stickiness $\alpha$. Observe that higher values of $\nu_{1}$ and $\varkappa_{1}$ (corresponding to higher price stickiness) imply a slower adjustment of $\widetilde{\mathcal{T}}_{t}+\widetilde{\Delta}_{t}$ as well as a slower adjustment of misalignment $\widetilde{\mathcal{Q}}_{t}$ and the demand gap $\widetilde{\mathcal{D}}_{t}$ under the optimal policy. We state useful relations between eigenvalues in the following Lemma. ${ }^{33}$

Lemma 1. For $0<\alpha<1$, the variables (eigenvalues) $\varkappa_{1}, \nu_{1}$ and $\varkappa_{2}, \nu_{2}$ are related as follows:

$$
\begin{gathered}
0<\frac{\left(\beta \varkappa_{2}-1\right)}{\beta \varkappa_{2}}<1, \quad 0<\frac{\left(\beta \nu_{2}-1\right)}{\beta \nu_{2}}<1, \\
\frac{\left(\beta \varkappa_{2}-1\right)}{\beta \varkappa_{2}}>\frac{\left(\beta \nu_{2}-1\right)}{\beta \nu_{2}} .
\end{gathered}
$$

The impact response to shocks and the ensuing dynamics under the optimal policy is derived

${ }^{33}$ Namely for $\varkappa_{1,2}$ :

$$
\varkappa_{1,2}=\frac{1+\beta+\frac{(1-\alpha \beta)(1-\alpha)}{\alpha} \theta \pm \sqrt{\left[1+\beta+\frac{(1-\alpha \beta)(1-\alpha)}{\alpha} \theta\right]^{2}-4 \beta}}{2 \beta}
$$

and $\nu_{1,2}$ differ from the above only in that the term $\frac{(1-\alpha \beta)(1-\alpha)}{\alpha}$ is not multiplied by $\theta$. As a result, we have the following relations:

$$
\begin{aligned}
& 0<\varkappa_{1}<1<\beta^{-1}+\frac{(1-\alpha \beta)(1-\alpha)}{\alpha \beta} \theta<\varkappa_{2} \\
& 0<\nu_{1}<1<\beta^{-1}+\frac{(1-\alpha \beta)(1-\alpha)}{\alpha \beta}<\nu_{2}, \\
& \varkappa_{2} \geq \nu_{2}
\end{aligned}
$$

It is worth noting that the eigenvalues $\varkappa_{2}$ and $\nu_{2}$ determine the discounted value of expectations of future fundamentals in driving the dynamics of the real exchange rate and of relative prices $\widetilde{\mathcal{T}}_{t}+\widehat{\Delta}_{t}$. Note that the lower the unstable eigenvalues $\varkappa_{2}$ and $\nu_{2}$, the less expected future fundamentals are discounted in determining the gaps. 
using the expressions in Table 3 and Lemma 1. Specifically, consider the world-economy response to news shocks at time $t_{0}$, resulting in capital inflows and a positive wedge gap $\widetilde{\mathcal{W}}_{t_{0}}>0$. The characterization of monetary policy follows evaluating the impact response of inflation in Table 3 , that is,

$$
\pi_{t_{0}}=-\left(1-a_{\mathrm{H}}\right) \frac{\left(\beta \varkappa_{2}-1\right)}{\theta \beta \varkappa_{2}} \widetilde{\mathcal{W}}_{t_{0}} \leq 0
$$

whereas the response of Foreign inflation is symmetric, $\pi_{t_{0}}^{*}=-\pi_{t_{0}}$. This establishes that, under the optimal cooperative policy, the monetary response is contractionary and deflationary at Home, while expansionary and inflationary abroad. Relative to a regime of strict CPI stability, optimal policy will thus focus on stabilizing relative demand, trading-off this objective for inflation and real exchange rate/misalignment variability (recall that, since $\widehat{\mathcal{Q}}_{t_{0}}^{f b}=0$ in response to news shocks, the welfare relevant gap and the real exchange rate move one-to-one: $\widetilde{\mathcal{Q}}_{t_{0}}=\widehat{\mathcal{Q}}_{t_{0}}$ ). We summarize the key properties of the allocation in the following proposition.

Proposition 7. In the Cole and Obstfeld economy with $\sigma=\phi=1$ and $\eta=0$, under $L C P$, in response to news shocks generating inefficient capital flows, the real exchange rate and CPI inflation are more volatile under the optimal policy than in a regime pursuing strict CPI stability; on impact the relative demand gap is less volatile while the output gap is smaller.

Proof. The proof follows from Table 3 and Lemma 1, evaluating the expressions in the table, without loss of generality, for a news shock at time $t_{0}$ resulting in a Home capital inflow and a positive wedge gap $\widetilde{\mathcal{W}}_{t_{0}}>0$. The fact that Home CPI inflation is not stabilized and falls on impact follows from (32).

The impact appreciation of the Home real exchange rate under the optimal policy follows from:

$$
\widetilde{\mathcal{Q}}_{t_{0}}=-\left[\left(2 a_{\mathrm{H}}-1\right) \frac{\left(\beta \varkappa_{2}-1\right)}{\beta \varkappa_{2}}+\frac{1}{\beta \varkappa_{2}}\right] \widetilde{\mathcal{W}}_{t_{0}}<0
$$

Since the expression in square brackets is greater than one, the impact appreciation is larger than under CPI price stability, whereas the expression for the real exchange rate under CPI stability coincides with $\widetilde{\mathcal{Q}}_{t}^{n a}=-\left(2 a_{\mathrm{H}}-1\right) \widetilde{\mathcal{W}}_{t}\left(\right.$ see Section 4.1.2). ${ }^{34}$

The result that relative demand $\widetilde{\mathcal{D}}_{t_{0}}$ is smaller than under strict CPI stability but still positive, follows from

$$
\widetilde{\mathcal{D}}_{t}^{n a}=2\left(1-a_{\mathrm{H}}\right) \widetilde{\mathcal{W}}_{t}>\widetilde{\mathcal{D}}_{t_{0}}=2\left(1-a_{\mathrm{H}}\right) \frac{\left(\beta \varkappa_{2}-1\right)}{\beta \varkappa_{2}} \widetilde{\mathcal{W}}_{t_{0}}>0
$$

whereas the first inequality holds since $\frac{\left(\beta \varkappa_{2}-1\right)}{\beta \varkappa_{2}}<1$, and we use the fact that the expression for the relative demand under CPI stability coincide with $\widetilde{\mathcal{D}}_{t}^{n a}$.

Finally, to show that the output gap is smaller than under strict CPI stability, we first

\footnotetext{
${ }^{34}$ It is worth observing that, dynamically, the optimal stance induces a predictable exchange rate dynamic, where Home real appreciation is followed by depreciation. To illustrate this dynamic, one can use the expression for $\widetilde{\mathcal{Q}}_{t}$ in Table 3 to decompose the movement of the exchange rate into a long-run permanent appreciation component and a component driven by the expected cumulated real interest rate differential across countries. Comparing the two, what determines this dynamic is the following inequality:

$$
\frac{1}{\beta \varkappa_{2}}>\left(2 a_{\mathrm{H}}-1\right) \frac{\left(\beta \varkappa_{2}-1\right)}{\beta \varkappa_{2}} \frac{\varkappa_{1}}{\left(1-\varkappa_{1}\right)}=\left(2 a_{\mathrm{H}}-1\right) \frac{1}{\beta \varkappa_{2}} .
$$

The expected appreciation in the long run reflects the permanent wealth effects associated with the capital inflow under incomplete markets.
} 
rewrite the expression in Table 3 as follows:

$$
\begin{aligned}
\widetilde{Y}_{H, t_{0}} & =2 a_{\mathrm{H}}\left(1-a_{\mathrm{H}}\right)\left(\widetilde{\mathcal{T}}_{t_{0}}+\widetilde{\Delta}_{t_{0}}\right)+1 / 2 \cdot\left(2 a_{\mathrm{H}}-1\right) \widetilde{\mathcal{D}}_{t_{0}} \\
& =\left(1-a_{\mathrm{H}}\right)\left[2 a_{\mathrm{H}}\left(\frac{\left(\beta \varkappa_{2}-1\right)}{\beta \varkappa_{2}}-\frac{\left(\beta \nu_{2}-1\right)}{\beta \nu_{2}}\right)-\frac{\left(\beta \varkappa_{2}-1\right)}{\beta \varkappa_{2}}\right] \widetilde{\mathcal{W}}_{t_{0}}
\end{aligned}
$$

and derive the output gap under strict CPI stability, $\tilde{Y}_{H, t_{0}}^{C P I}$, given by:

$$
\widetilde{Y}_{H, t_{0}}^{C P I}=\left(1-a_{\mathrm{H}}\right)\left[2 a_{\mathrm{H}}\left(1-\frac{\left(\beta \nu_{2}-1\right)}{\beta \nu_{2}}\right)-1\right] \widetilde{\mathcal{W}}_{t_{0}}
$$

The result directly follows from comparing the two expressions using Lemma 1. Observe that, by Lemma 1 and since $\nu_{2}<\varkappa_{2}$, neither the output gap under the optimal policy nor $\widetilde{Y}_{H, t_{0}}^{C P I}$ is necessarily negative (i.e., $\widetilde{Y}_{H, t_{0}} \lesseqgtr 0$, and $\widetilde{Y}_{H, t_{0}}^{C P I} \lesseqgtr 0$ )

The proposition establishes that in response to a capital inflow, the (constrained-) optimal contractionary stance at Home matched by the expansion abroad contains the inefficient surge in Home consumption relative to the Foreign one. However, concerns about inflation stabilization implies the cooperative policy falls short of closing the demand gap. Moreover, the Home output gap is always lower than under strict CPI stabilization, though not necessarily negative. Looking at the expression for the output gap in Table 3, a positive output gap is possible if the positive impact of the capital inflow on the relative demand gap, $\widetilde{\mathcal{D}}_{t_{0}}$ outweighs the negative (and exogenous) effect of the terms-of-trade gap and deviations from the LOOP, $\widetilde{\mathcal{T}}_{t_{0}}+\widetilde{\Delta}_{t_{0}}$. In this case, the volatility of the output gap is always smaller under the optimal policy than under CPI stabilization. It is easy to see that, on impact, the output gap is positive if the following condition is satisfied:

$$
\frac{\beta \varkappa_{2}-1}{\frac{\beta \varkappa_{2}}{\beta \nu_{2}}-1}<2 a_{\mathrm{H}} .
$$

This condition is more likely to hold in economies that are quite closed (i.e., economies with a high home bias $\left.a_{\mathrm{H}}\right)$-intuitively, openness increases the relative weight of $\left(\widetilde{\mathcal{T}}_{t_{0}}+\widetilde{\Delta}_{t_{0}}\right)$ and decreases that of $\widetilde{\mathcal{D}}_{t_{0}}$ in the output gap expression above. Strikingly, the inequality is always violated (for any degree of openness), in the limit case where prices are very flexible $\left(\varkappa_{2} \simeq \nu_{2} \rightarrow \infty\right){ }^{35}$

Together, these results establish that in the CO economy, LCP motivates monetary authorities to optimally trade off stabilization of domestic demand (and in less open economies the output gap) with inflation and real exchange rate volatility. We conclude this section by exploring how the policy and the dynamics change with the degree of nominal rigidities (and thus exchange rate pass-through) and openness. As stated in the following corollary, it turns out that both have similar implications for the equilibrium response of the exchange rate: exchange rate volatility is higher in less open economies (larger $a_{\mathrm{H}}$ ) with less price stickiness (smaller $\alpha$ ).

Corollary 3. The impact response of the real exchange rate in (33) and of the demand gap

\footnotetext{
${ }^{35}$ When $\widehat{\mathcal{W}}_{t_{0}}<0$ - e.g. due to contemporaneous taste shocks - Home monetary policy is relatively expansionary to stimulate the inefficiently low domestic consumption. Relative to the above, the response of optimal monetary policy is the opposite, because capital inflows are now inefficiently low. The real exchange rate depreciates and is undervalued. However, undervaluation is lower with a high degree of pass-through and openness.
} 
in (35) are, respectively, increasing and decreasing in $\alpha>0$ and $a_{\mathrm{H}} \geq 1 / 2$.

Intuitively, for a given exogenous wealth gap $\widetilde{\mathcal{W}}_{t_{0}}$, as the economy becomes less open, domestic monetary policy becomes more concerned in dealing with a demand boom fueled by capital inflows, for any given degree of price stickiness, at the expense of larger misalignment. By the same token, if prices become stickier, implying less exchange rate pass-through, optimal monetary policy is less concerned with redressing misalignment, since exchange rate movements are less consequential for the domestic output gap. On the contrary, it attaches a larger weight on aggregate demand stabilization. ${ }^{36}$

\subsection{Exchange rate stabilization and competitiveness with complete pass- through (PCP economies)}

A comparison of our results across LCP and PCP economies is particularly suitable in the Cole-and-Obstfeld specification, since in response to identical shocks, the sign and size of the ensuing capital flows and wealth gap - that is, the expressions for $\widehat{\mathcal{B}}_{t}$ and $\widetilde{\mathcal{W}}_{t}$ in (31) and (30)are exactly the same. Conditional on a given $\widehat{\mathcal{B}}_{t}<0$ and the associated $\widetilde{\mathcal{W}}_{t}$ (always positive when preference shocks are anticipated), Table 4 presents the allocation under the optimal cooperative monetary policy for the PCP economy.

$$
\begin{aligned}
& \text { Table 4: Constrained-efficient allocation under PCP in the CO economy } \\
& \widetilde{Y}_{H, t}=-\left(1-a_{\mathrm{H}}\right) \frac{\left(\beta \varkappa_{2}-1\right)}{\beta \varkappa_{2}} \widetilde{\mathcal{W}}_{t}+\varkappa_{1} \widetilde{Y}_{H, t-1} \\
& \theta \pi_{H, t}=\left(1-a_{\mathrm{H}}\right) \frac{\left(\beta \varkappa_{2}-1\right)}{\beta \varkappa_{2}} \widetilde{\mathcal{W}}_{t}+\left(1-\varkappa_{1}\right) \widetilde{Y}_{H, t-1} \\
& \widetilde{\mathcal{T}}_{t}=-\left(1-\frac{2\left(1-a_{\mathrm{H}}\right)}{\beta \varkappa_{2}}\right) \widetilde{\mathcal{W}}_{t}+2 \varkappa_{1} \widetilde{Y}_{H, t-1} \\
& \widetilde{\mathcal{Q}}_{t}=-\left(2 a_{\mathrm{H}}-1\right)\left[\left(1-\frac{2\left(1-a_{\mathrm{H}}\right)}{\beta \varkappa_{2}}\right) \widetilde{\mathcal{W}}_{t}-2 \varkappa_{1} \widetilde{Y}_{H, t-1}\right] \\
& \widetilde{\mathcal{D}}_{t}=2\left(1-a_{\mathrm{H}}\right)\left[1+\frac{\left(2 a_{\mathrm{H}}-1\right)}{\beta \varkappa_{2}}\right] \widetilde{\mathcal{W}}_{t}+2\left(2 a_{\mathrm{H}}-1\right) \varkappa_{1} \widetilde{Y}_{H, t-1}
\end{aligned}
$$

The Home optimal monetary response to inefficient capital flows is the opposite relative to the LCP case - since the wealth gap enters the expression for PPI inflation with the opposite sign. In response to news shocks at time $t_{0}$, resulting in capital inflows and a positive wealth gap $\widetilde{\mathcal{W}}_{t_{0}}>0$, the optimal cooperative policy response is expansionary and inflationary at Home, while contractionary and deflationary abroad. Under PCP, misalignment and output gaps are directly related, in contrast to LCP. In general, as formally stated by the following proposition, relative to a regime of strict GDP deflator stability, the optimal policy trades off higher inflation variability for better stabilization of the output gap and misalignment.

Proposition 8. In the Cole and Obstfeld economy with $\sigma=\phi=1$ and $\eta=0$, under $P C P$, in response to news shocks generating inefficient capital flows, the relative demand gap and GDP deflator are more volatile under the optimal policy than in a regime pursuing strict inflation stability; the real exchange rate and the output gap are less volatile on impact.

Proof. Consider again news shocks that cause $\widetilde{\mathcal{B}}_{t_{0}}<0$ and $\widetilde{\mathcal{W}}_{t_{0}}>0$, without loss of generality. When exchange rate pass-through is complete, under the optimal policy the short-

\footnotetext{
${ }^{36}$ But note: as prices become more sticky, the equilibrium rate of inflation (32) becomes less volatile, since with higher nominal rigidities prices react less strongly to the asymmetric world monetary stance.
} 
run (GDP deflator) inflation is positive

$$
\pi_{H, t_{0}}=\left(1-a_{\mathrm{H}}\right) \frac{\left(\beta \varkappa_{2}-1\right)}{\theta \beta \varkappa_{2}} \widetilde{\mathcal{W}}_{t_{0}}>0
$$

Compared with Table 2, the combination of Home expansion and foreign contraction mitigates, without reversing, the exchange rate appreciation and misalignment:

$$
\widetilde{\mathcal{Q}}_{t_{0}}=-\left(2 a_{\mathrm{H}}-1\right)\left(1-\frac{2\left(1-a_{\mathrm{H}}\right)}{\beta \varkappa_{2}}\right) \widetilde{\mathcal{W}}_{t_{0}}<0
$$

where in the natural allocation $\widetilde{\mathcal{Q}}_{t_{0}}^{n a}=-\left(2 a_{\mathrm{H}}-1\right) \widetilde{\mathcal{W}}_{t_{0}}$. The expansionary stance makes the Home output gap less negative than $\widetilde{Y}_{H, t}^{n a}=-\left(1-a_{\mathrm{H}}\right) \widetilde{\mathcal{W}}_{t}$, namely:

$$
\widetilde{Y}_{H, t_{0}}=-\left(1-a_{\mathrm{H}}\right) \frac{\left(\beta \varkappa_{2}-1\right)}{\beta \varkappa_{2}} \widetilde{\mathcal{W}}_{t_{0}}<0
$$

(this is so because $\left.\frac{\left(\beta \varkappa_{2}-1\right)}{\beta \varkappa_{2}}<1\right)$; while the relative demand gap is larger than $\widetilde{\mathcal{D}}_{t}^{n a}=$ $2\left(1-a_{\mathrm{H}}\right) \widetilde{\mathcal{W}}_{t}$, namely:

$$
\widetilde{\mathcal{D}}_{t_{0}}=2\left(1-a_{\mathrm{H}}\right)\left[1+\frac{\left(2 a_{\mathrm{H}}-1\right)}{\beta \varkappa_{2}}\right] \widetilde{\mathcal{W}}_{t_{0}}>0
$$

When exchange rate pass-through is complete, capital inflows prompt Home monetary authorities to optimally implement a monetary expansion. Compared with the natural rate allocation in Table 2, on impact they tolerate some short-run (GDP deflator) inflation. Indeed, they lean on the appreciation of the real exchange rate so as to contain competitiveness losses. Relative to the natural allocation, the expansionary stance stabilizes the output gap - which is however always negative - but widen the relative demand gap. The optimal degree of monetary expansion again depends on whether the economy is more or less open, and the degree of price stickiness. Specifically, the real exchange rate is more volatile if home bias is larger and if prices are more flexible.

\subsection{Exchange rate volatility, inflation and output gaps: a comparison of LCP and PCP economies}

To offer further insight on the difference between LCP and PCP and the role of exchange rate pass-through, we now carry out a synthetic comparison of macroeconomic dynamics under the optimal policy. Figure 1 plots the impulse responses of the relevant gaps to a preference shock anticipated to occur 20 quarters in the future (intentionally outside the time scale of the graph), causing an immediate inflow of capital in the Home economy. The shock is normalized to produce an initial capital inflow as high as 1 percent of Home GDP. ${ }^{37}$

Recall that both the capital inflows and the wealth gap are exogenous to macroeconomic adjustment and policy, hence independent of LCP and PCP. As shown by the first graph in the upper left corner, the stock of foreign debt increases exogenously along the optimal adjustment path. The size of capital flows is excessive: the wealth gap (shown in the graph in the upper

\footnotetext{
${ }^{37}$ The parameter values are as follows: $\eta=0, \phi=\sigma=1, a_{\mathrm{H}}=.75, \beta=.99, \alpha=.75, \theta=3$.
} 
right corner) jumps to a positive value and remains constant, according to (15).

The remaining graphs in the figure distinguish between LCP economies (continuous lines) and PCP economies (dashed lines). The price response (lower left corner) shows that the monetary stance is relatively expansionary under PCP (GDP-deflator inflation is positive), contractionary under LCP (CPI inflation is negative).

Comparing the two economies highlights a key result from our analysis of the CO economy. Given identical shocks and parameters (but for import price stickiness), under the optimal policy, the real exchange rate is always less volatile under PCP (where monetary authorities lean against appreciation) than under LCP (where monetary authorities exacerbate misalignment). Analytically, this follows from observing that under strict inflation targeting, the real exchange rate response under LCP (CPI targeting) is the same as under PCP (GDP deflator targeting), and thus equal to the natural rate allocation $\widehat{\mathcal{Q}}_{t}^{n a}=-\left(2 a_{\mathrm{H}}-1\right) \widetilde{\mathcal{W}}_{t}$. Relative to this natural rate allocation, we have shown that the optimal policy makes the real exchange rate less volatile under PCP, and more volatile under LCP. Correspondingly, the real exchange rate always undershoots its long-run value under PCP - and overshoots under LCP. Nonetheless, note that, because of the expenditure-switching effects of the exchange rate, the output gap is more negative under PCP, in spite of the expansionary policy stance. ${ }^{38}$

\subsection{Discussion}

Three comments are in order about how incomplete markets impinge on the optimal policy. First, in Section 3.2 we observed that $\widetilde{\mathcal{W}}_{t}$ characterizes a specific trade-off between leaning against misalignment $\widetilde{\mathcal{Q}}_{t}$ and redressing a relative demand gap $\widetilde{\mathcal{D}}_{t}$. In this section, we have shown that, in CO economies where $\widetilde{\mathcal{W}}_{t}$ is exogenous, this trade-off is resolved differently under LCP and PCP. Under LCP, optimal monetary policy focuses on stabilizing $\widetilde{\mathcal{D}}_{t}$ and domestic demand at the expense of higher volatility in misalignment - due to incomplete pass through the exchange rate has limited expenditure switching effects and thus $\widetilde{\mathcal{Q}}_{t}$ has little impact on output gaps. Conversely, when pass-through is complete (under PCP) $\widetilde{\mathcal{Q}}_{t}$ greatly affects output gaps, and optimal monetary policy thus focuses on stabilizing misalignment, at the expense of higher volatility in $\widetilde{\mathcal{D}}_{t}$ and domestic demand.

Second, when discussing the Phillips curves (21), we stressed that the wealth gap is 'isomorphic' to exogenous markup shocks. However, wealth gaps and markup shocks elicit very different monetary policy responses. From the literature, we know that the Home response to an exogenous inflationary markup shock that causes real appreciation is always contractionary, irrespective of LCP and PCP. ${ }^{39}$ Conversely, from the analysis in this section, we have seen that the Home policy response to appreciation following capital inflows is expansionary under PCP, but contractionary under LCP.

As a final comment, we should observe that, while our results are derived under commitment, they can be brought to bear on the case of cooperation under discretion. ${ }^{40}$ In general, the

\footnotetext{
${ }^{38}$ Analytically, this follows from comparing the expression for the output gaps under PCP, the natural allocation and LCP, whereas, since $\nu_{2}<\varkappa_{2}$,

$$
\left(1-a_{\mathrm{H}}\right) \frac{\left(\beta \varkappa_{2}-1\right)}{\beta \varkappa_{2}}>\left(1-a_{\mathrm{H}}\right)\left[2 a_{\mathrm{H}} \frac{\left(\beta \nu_{2}-1\right)}{\beta \nu_{2}}-\frac{\left(\beta \varkappa_{2}-1\right)}{\beta \varkappa_{2}}\right]>\left(1-a_{\mathrm{H}}\right)\left[1-2 a_{\mathrm{H}}\left(1-\frac{\left(\beta \nu_{2}-1\right)}{\beta \nu_{2}}\right)\right] .
$$

${ }^{39}$ This is a well-known result in the literature under complete markets, see, e.g., Engel [2011] or CDL [2010].

${ }^{40}$ Under discretion, policymakers are not able to improve the short-run trade-offs among competing goals by
} 
analytical characterization of the targeting rules under discretion is complicated by the need to account for the fact that optimal policy is a function of, and at the same time affects, the dynamic of foreign debt accumulation. However, when capital flows and wealth gaps are exogenous to monetary policy, as is the cased in the $\mathrm{CO}$ economy, the targeting rules under discretion can be easily derived from the rules under commitment given above-simply crossing out lagged terms.

\section{Beyond pass-through: optimal policy with over/under appre- ciation}

In what follows we relax some of the parameters restrictions of the $\mathrm{CO}$ economy, so to extend our analysis in three directions. First, unlike the CO economy, capital flows may no longer be exogenous to monetary policy. We can thus characterize how optimal monetary policy affects the size of inefficient cross-border borrowing and lending (see Section 3.2 for the effects of a monetary policy shock). Second, cross-border flows will respond to other shocks, including productivity (or possibly markups shocks), in addition to shocks to preferences for saving (or changes in taxes or capital controls). We can thus consider different types of business cycle disturbances. Finally, in response to news shocks, the wealth gap $\widetilde{\mathcal{W}}_{t}$ associated with excessive capital inflows (relative to the first-best allocation) will not be necessarily positive - i.e., capital inflows may lead to undervaluation of the exchange rate and depress relative domestic demand.

Throughout this section, we will reconsider our analysis without restricting $\phi$, but, for tractability of the LCP case, we will impose $\eta=0$ and $\sigma=1{ }^{41}$ To keep the analytical complexity at a minimum, we continue to focus on "news shocks" only-no contemporaneous shocks will appear in the equations to follows. ${ }^{42}$

The core conclusion from our analysis is that most insights from the CO economy-in particular, that the degree of exchange rate pass-through is the crucial determinant of the optimal monetary response to capital flows - will go through as long as $\widetilde{\mathcal{W}}_{t}$ and capital flows $\widehat{\mathcal{B}}_{t}$ move in opposite directions in response to news shocks. When $\widetilde{\mathcal{W}}_{t}$ and $\widehat{\mathcal{B}}_{t}$ have the same sign, instead, ERPT is no longer crucial in determining the direction of the optimal monetary stance. The difference rests on key features of the international transmission shaping the equilibrium link between $\widetilde{\mathcal{W}}_{t}$ and $\widehat{\mathcal{B}}_{t}$.

\subsection{Wealth gaps and capital flows: insight from the transfer problem}

Under incomplete markets, capital inflows into Home result in a transfer of purchasing power from abroad, reflecting endogenously higher savings by Foreign residents or higher dissaving

credibly guiding expectations of future policy rates and inflation. In the closed economy counterpart of our model, or in its version under complete markets, optimal targeting rules derived under discretion will be the same as the ones derived under commitment, except that all variables (but for inflation) will be in levels, rather than in growth rates. In a bond economy, however, the accumulation of net foreign assets and liabilities changes the state of the economy over time.

${ }^{41}$ Under PCP it is possible to derive analytically tractable results for any $\eta \geq 0$ and $\sigma \geq 0$, as shown in the appendix.

${ }^{42}$ This is without loss of generality as contemporaneous shocks mainly affect the relation between capital flows and the sign of the wealth gap; nevertheless, given the latter, the optimal monetary policy response is the same for both contemporaneous and anticipated shocks. 
by Home residents. As already noted, from a global perspective, since there is home bias in demand, if relative prices and incomes did not adjust, the transfer would translate into an excess supply of Foreign goods. Equilibrium unavoidably requires adjustment in relative prices and incomes. The way this adjustment takes place depends on the relative strength of income and substitution effects from capital inflows, and thus on the trade elasticity in the workhorse open macro model.

When trade elasticities are sufficiently large, substitution effects from real exchange rate movements are stronger than income effects. In equilibrium, adjustment to a transfer from Foreign to Home requires Home real appreciation. Because of the fall in the relative price of Foreign output, Foreign real income falls and Home real income rises by more than the size of the transfer at constant prices - the "transfer problem" discussed by Keynes in the classical controversy with Ohlin about the effects of war reparation payments on the terms of trade of a country (see Keynes [1929] and Ohlin [1929]). The appreciation compounds the rise in Home relative wealth from the transfer, strengthening the positive response of $\widetilde{\mathcal{W}}_{t}$ to inflows.

The equilibrium adjustment is quite different if income effects from relative price adjustment are stronger than substitution effects - corresponding to relatively high home bias and strong complementarity between Home and Foreign goods (i.e., a low trade elasticity). In response to Home capital inflows there is no equilibrium with Home appreciation/Foreign depreciation, because this would drive Foreign demand too low for the goods markets to clear at global level. Instead, equilibrium requires Foreign appreciation/Home depreciation, with the effect of reducing Home relative wealth-driving $\widetilde{\mathcal{W}}_{t}<0$ in spite of the transfer (see, e.g., CDL [2008a]).

To appreciate how the interplay of income and substitution effects impinge on the equilibrium, a good starting point is a reconsideration of the natural rate (flex price) allocation, when the trade elasticity is no longer constrained to be unity (but $\eta=0$ and $\sigma=1$ ). Setting $\phi \neq 1$ has the following implications for the allocation shown in Table 2 (see subsection 4.1.2). After a news shock to either productivity or technology, on impact capital flows and the wealth gap obey the following relation:

$$
-\left(1-a_{\mathrm{H}}\right)\left[2 a_{\mathrm{H}}(\phi-1)+1\right] \widetilde{\mathcal{W}}_{t_{0}}^{n a}=\widehat{\mathcal{B}}_{t_{0}}^{n a} .
$$

Given news shocks leading to capital inflows $\left(\widehat{\mathcal{B}}_{t_{0}}^{n a}=\widetilde{\mathcal{B}}_{t_{0}}^{n a}<0\right)$, the associated wealth gap $\left(\widetilde{\mathcal{W}}_{t_{0}+j}^{n a}=\widetilde{\mathcal{W}}_{t_{0}}^{n a}, j \geq 0\right)$ may be positive or negative, depending on the value of the trade elasticity and openness. Specifically, there is a threshold value for the trade elasticity as a function of openness, beyond which, if $\widehat{\mathcal{B}}_{t_{0}}^{n a}<0$, then $\widetilde{\mathcal{W}}_{t_{0}}^{n a}>0$. This threshold value is given by:

$$
\phi>\frac{2 a_{\mathrm{H}}-1}{2 a_{\mathrm{H}}} \leq 1 / 2 .
$$

Note that $\left(2 a_{\mathrm{H}}-1\right) / 2 a_{\mathrm{H}} \rightarrow 0$ when $a_{\mathrm{H}} \rightarrow 1 / 2$, that is, the wealth gap associated with excessive capital inflows is always positive in economies with no home bias in demand. However, in response to a capital inflow, the output gap, given by:

$$
\widetilde{Y}_{H, t}^{n a}=-\left(1-a_{\mathrm{H}}\right)\left[2 a_{\mathrm{H}}(\phi-1)+1\right] \widetilde{\mathcal{W}}_{t_{0}}^{n a}=\widehat{\mathcal{B}}_{t_{0}}^{n a}<0
$$

is always negative for any $\phi$ under home bias. 
Remarkably, however, once the sign and size of the wealth gap is determined, all the welfare relevant gaps - with the notable exception of the output gap - are exactly the same as in Table 2. In other words, but for the output gap, as long as $\eta=0$ and $\sigma=1$, the natural allocation in the presence of news shock to technology and preferences depends on the elasticity $\phi$ only through the response of the wealth gap.

Here is the "transfer problem" at play in the natural allocation: as shown in Table 2, for a positive wealth gap, capital inflows appreciate the exchange rate, the Home currency is overvalued and Home domestic demand is excessive. The opposite is true for elasticities below the threshold (36): with a negative wealth gap, capital inflows are associated with real depreciation and the Home real exchange rate is undervalued; Home demand is not high enough. In either case, the output gap remains negative - either because of the overvaluation, or because domestic demand relative to foreign is too low.

The relative strength of income relative to substitution effects has a key implication for monetary policy design. As shown below, in relatively open economies where the trade elasticity is sufficiently bounded away from zero, so that a "transfer" $\widehat{\mathcal{B}}_{t}<0$ leads to $\widetilde{\mathcal{W}}_{t}>0$, the optimal policy prescriptions will be the same as the one derived for the $\mathrm{CO}$ economy and depend on ERPT (see subsections 5.2 and 5.3). Conversely, in relatively closed economies with a sufficiently low elasticity, so that $\widehat{\mathcal{B}}_{t}<0$ and $\widetilde{\mathcal{W}}_{t}<0$, sustaining domestic demand and output in response to capital inflows and currency undervaluation becomes the overriding concern of monetary policy. The optimal monetary stance will be expansionary for any degree of exchange rate pass-through (see subsection 5.4). ${ }^{43}$

\subsection{Incomplete pass-through (LCP) economies}

From proposition 5 above, we know that, with LCP, under our parameter restrictions capital flows and the associated wealth gap remain exogenous to policy even if the trade elasticity is different from unity (the case of $\mathrm{CO}$ economies). This is apparent from Table 5, where we show the equilibrium relation between capital flows and the wealth gap under LCP, together with the full solution for the dynamics of capital flows. The two expressions in the table depend only on exogenous shocks, and on the current and anticipated future evolution of relative prices in the first-best allocation through the term $\mathcal{Z}_{t}$, unaffected by policy. ${ }^{44}$

\footnotetext{
${ }^{43} \mathrm{~A}$ variety of financial market imperfections and frictions can in principle generate capital inflows that result in a decrease in wealth, by strengthening income effects over substitution effects from exchange rate movements. It is worth stressing that the results in the text would not hold under complete markets: perfect risk diversification would eliminate any adverse income effects from shocks and exchange rate movements.

${ }^{44}$ Specifically:

$$
\begin{aligned}
& \mathcal{Z}_{t}=2 a_{\mathrm{H}}\left(1-a_{\mathrm{H}}\right)(\phi-1) \sum_{j=0}^{\infty} \nu_{2}^{-j-1} E_{t}\left[\left(\widehat{\mathcal{T}}_{t+j+1}^{f b}-\widehat{\mathcal{T}}_{t+j}^{f b}\right)-\beta^{-1}\left(\widehat{\mathcal{T}}_{t+j}^{f b}-\widehat{\mathcal{T}}_{t+j-1}^{f b}\right)\right] \\
& -2 a_{\mathrm{H}}\left(1-a_{\mathrm{H}}\right)(\phi-1)\left[\frac{1+2 a_{\mathrm{H}}(\phi-1) \frac{\left(\beta \nu_{2}-1\right)}{\beta \nu_{2}}}{\left.1+2 a_{\mathrm{H}}(\phi-1) \frac{\left(\beta \nu_{2}-1\right)}{\beta \nu_{2}(1-\beta \nu}\right)}\right] \cdot\left\{\beta \sum_{j=0}^{\infty} \beta^{j} E_{t}\left[\left(\widehat{\mathcal{T}}_{t+j+1}^{f b}-\widehat{\mathcal{T}}_{t+j}^{f b}\right)\right]+\right. \\
& \left.\sum_{j=0}^{\infty} \beta^{j}\left[\begin{array}{c}
\sum_{s=0}^{\infty} \nu_{2}^{-s-1} E_{t} \\
-\left(1-\nu_{1}\right) \beta\left[\widehat{\mathcal{T}}_{t+j+s+1}^{f b}-\widehat{\mathcal{T}}_{t+j+s}^{f b}\right)-\beta^{-1}\left(\widehat{\mathcal{T}}_{t+j+s}^{f b}-\widehat{\mathcal{T}}_{t+j+s-1}^{f b}\left(\sum_{h=0}^{\infty} \nu_{2}^{-h-1} E_{t}\left[\left(\widehat{\mathcal{T}}_{t+h+s+1}^{f b}-\widehat{\mathcal{T}}_{t+h+s}^{f b}\right)-\beta^{-1}\left(\widehat{\mathcal{T}}_{t+h+s}^{f b}-\widehat{\mathcal{T}}_{t+h+s-1}^{f b}\right)\right]\right)\right]
\end{array}\right]\right\}
\end{aligned}
$$
}


Table 5: Capital flows under LCP and with news shocks for $\phi \geq 0$

$$
\begin{aligned}
& \left(1-a_{\mathrm{H}}\right)\left[1+2 a_{\mathrm{H}}(\phi-1) \frac{\left(\beta \nu_{2}-1\right)}{\beta \nu_{2}}\right] \widetilde{\mathcal{W}}_{t}=-\left(\widehat{\mathcal{B}}_{t}-\beta^{-1} \widehat{\mathcal{B}}_{t-1}\right)+ \\
& 2 a_{\mathrm{H}}\left(1-a_{\mathrm{H}}\right)(\phi-1) \sum_{j=0}^{\infty} \nu_{2}^{-j-1} E_{t}\left[\left(\widehat{\mathcal{T}}_{t+j+1}^{f b}-\widehat{\mathcal{T}}_{t+j}^{f b}\right)-\beta^{-1}\left(\widehat{\mathcal{T}}_{t+j}^{f b}-\widehat{\mathcal{T}}_{t+j-1}^{f b}\right)\right] \\
& \widehat{\mathcal{B}}_{t}-\widehat{\mathcal{B}}_{t-1}=\frac{2 a_{\mathrm{H}}(\phi-1) \frac{\left(\beta \nu_{2}-1\right) \nu_{1}}{\nu_{2}\left(1-\beta \nu_{1}\right)}}{1+2 a_{\mathrm{H}}(\phi-1) \frac{\left(\beta \nu_{2}-1\right)}{\beta \nu_{2}\left(1-\beta \nu_{1}\right)}}\left(\beta^{-1} \widehat{\mathcal{B}}_{t-1}-\widehat{\mathcal{B}}_{t-1}\right)+\mathcal{Z}_{t}+ \\
& {\left[\frac{1+2 a_{\mathrm{H}}(\phi-1) \frac{\left(\beta \nu_{2}-1\right)}{\beta \nu_{2}}}{1+2 a_{\mathrm{H}}(\phi-1) \frac{\left(\beta \nu_{2}-1\right)}{\beta \nu_{2}\left(1-\beta \nu_{1}\right)}}\right] \beta \sum_{j=0}^{\infty} \beta^{j} E_{t}\left[\left(\widehat{\zeta}_{C, t+j+1}-\widehat{\zeta}_{C, t+j+1}^{*}\right)-\left(\widehat{\zeta}_{C, t+j}-\widehat{\zeta}_{C, t+j}^{*}\right)\right]}
\end{aligned}
$$

Inspection of Table 5 establishes that the trade elasticity $\phi$ is a key determinant of the joint response of $\widehat{\mathcal{B}}_{t}$ and $\widetilde{\mathcal{W}}_{t}$ to news shocks in two respects. First, $\phi$ determines whether a given "news shock" translates into inefficient borrowing or lending; second, it determines whether $\widehat{\mathcal{B}}_{t}$ and $\widetilde{\mathcal{W}}_{t}$ have the same or the opposite sign, which is crucial for the optimal monetary stance. Differently from the case of the natural allocation, it turns out that, under LCP, the threshold value of the trade elasticity above which $\widehat{\mathcal{B}}_{t}$ and $\widetilde{\mathcal{W}}_{t}$ have the opposite sign is conditional on which shocks hit the economy. Leaving derivations to the appendix, conditional on anticipated taste shocks, $\widehat{\mathcal{B}}_{t}$ and $\widetilde{\mathcal{W}}_{t}$ have the opposite sign when $\phi$ is above the following threshold:

$$
\phi>\frac{2 a_{\mathrm{H}}-\frac{\beta \nu_{2}}{\left(\beta \nu_{2}-1\right)}}{2 a_{\mathrm{H}}}
$$

which is a function of openness and nominal rigidities and is always bounded above by (36). For anticipated productivity shocks, the equilibrium link between $\widehat{\mathcal{B}}_{t}$ and $\widetilde{\mathcal{W}}_{t}$ depends also on the specific process governing productivity.

Given the sign and evolution of $\widehat{\mathcal{B}}_{t}$ and $\widetilde{\mathcal{W}}_{t}$ in response to shocks, however, $\phi$ does not enter directly the expressions for the response of inflation, demand gaps and the real exchange rate, which are the same as in Table 3 of Section 4.2. Only the output gap differs from the one in Table 3 , in that it depends directly on $\phi$. We characterize the impact response to news shocks under the optimal policy in the following proposition - which generalizes the results stated in proposition 3 for $\phi=1$.

Proposition 9. Under $L C P$, with $\sigma=1, \eta=0$ and $\phi \geq 0$, in response to news shocks generating inefficient capital flows, the real exchange rate and CPI inflation are more volatile under the optimal policy than in a regime pursuing strict CPI stability; on impact the relative demand gap is less volatile while the output gap is smaller.

Proof. As shown in the appendix, the allocation is the same as the one derived in the Table 3 , but for the output gap. So relevant results from Proposition 7 also apply here. The impact response of the output gap is given by the following expression:

$$
\widetilde{Y}_{H, t_{0}}=\left(1-a_{\mathrm{H}}\right)\left[\left(2 a_{\mathrm{H}}-1\right) \frac{\left(\beta \varkappa_{2}-1\right)}{\beta \varkappa_{2}}-2 a_{\mathrm{H}} \phi \frac{\left(\beta \nu_{2}-1\right)}{\beta \nu_{2}}\right] \widetilde{\mathcal{W}}_{t_{0}}
$$

Comparing the above expression with the output gap response under CPI price stability:

$$
\widetilde{Y}_{H, t_{0}}^{C P I}=\left(1-a_{\mathrm{H}}\right)\left[\left(2 a_{\mathrm{H}}-1\right)-2 a_{\mathrm{H}} \phi \frac{\left(\beta \nu_{2}-1\right)}{\beta \nu_{2}}\right] \widetilde{\mathcal{W}}_{t_{0}}
$$


the result that $\widetilde{Y}_{H, t_{0}}<\widetilde{Y}_{H, t_{0}}^{C P I}$ follows from noting that $0<\frac{\left(\beta \varkappa_{2}-1\right)}{\beta \varkappa_{2}}<1$ for $\alpha>0$

While the volatility ranking established by the proposition holds for any $\phi$, monetary policy prescriptions actually differ depending on the value of the trade elasticity and the type of shocks. Provided that in response to shocks that cause a capital inflow, $\widehat{\mathcal{B}}_{t}<0$, the wealth gap turns positive, $\widetilde{\mathcal{W}}_{t}>0$, the sign of the optimal policy response is the same as in the CO economy. In response to anticipated tastes shocks, this would be the case for an elasticity above (38). The Home monetary authorities implement a monetary tightening, letting inflation decline, at the cost of exacerbating the Home real exchange rate overappreciation in the short run. ${ }^{45}$ Differently from Section 4.2, however, the optimal contractionary stance does not necessarily bring the output gap into negative territory, depending on $\phi$. Using expression (39), it is easy to show that the output gap is negative when $\phi$ is sufficiently above 1.

These results are illustrated by the graphs in the first column of Figure 2 where, assuming (anticipated shocks resulting in $\widehat{\mathcal{B}}_{t}<0$ and) the same positive value of $\widetilde{\mathcal{W}}_{t}$ as in Figure 1, a solid blue line traces the impulse responses of misalignment, CPI level and the output gap in a LCP economy with $\phi=2$ (while keeping other parameters as in Figure 1). While the response of the misalignment and the price level is the same as in the CO economy, a higher value of the trade elasticity translates into a more negative and volatile output gap.

For a trade elasticity below the thresholds (38), in response to inflows $\left(\widehat{\mathcal{B}}_{t}<0\right)$ the wealth gap turns negative $\left(\widetilde{\mathcal{W}}_{t}<0\right)$, and the monetary stance switches sign, becoming expansionary at Home and contractionary abroad. This case, shown in the second column of Figure 2, will be considered in the Subsection 5.4 below.

\subsection{Complete pass-through (PCP) economies}

When exchange rate pass-through is complete, in contrast to LCP, capital flows and the wealth gap are no longer independent of the macroeconomic allocation and policy once the trade elasticity deviates from unity. As shown in Section 3.1.3, the optimal monetary stance affects the size of the inflows and $\widetilde{\mathcal{W}_{t}}$ even for $\sigma=1$.

As a first step in our analysis, in the following Lemma we characterize how shocks affect capital flows under the optimal policy in comparison with the natural allocation.

Lemma 2. For $\sigma=1, \eta=0, \phi \geq 0$, capital inflows in the constrained-efficient allocation are given by the following expression:

$$
\begin{aligned}
& \widehat{\mathcal{B}}_{t}=\widehat{\mathcal{B}}_{t-1}+ \\
& -\frac{\left(1-a_{\mathrm{H}}\right)}{4 a_{\mathrm{H}}\left(1-a_{\mathrm{H}}\right)(\phi-1)+1} \cdot \mathbf{B} \beta \sum_{j=0}^{\infty} \beta^{j}\left[\begin{array}{c}
2 a_{\mathrm{H}}(\phi-1) E_{t}\left(\left(\widehat{Y}_{H, t+j+1}^{f b}-\widehat{Y}_{F, t+j+1}^{f b}\right)-\left(\widehat{Y}_{H, t+j}^{f b}-\widehat{Y}_{F, t+j}^{f b}\right)\right)+ \\
-\left(2 a_{\mathrm{H}}(\phi-1)+1\right) E_{t}\left(\left(\widehat{\zeta}_{C, t+1+j}-\widehat{\zeta}_{C, t+1+j}^{*}\right)-\left(\widehat{\zeta}_{C, t+j}-\widehat{\zeta}_{C, t+j}^{*}\right)\right)
\end{array}\right]+ \\
& \quad 2\left(1-a_{\mathrm{H}}\right)\left[\frac{2 a_{\mathrm{H}}(\phi-1)}{4 a_{\mathrm{H}}\left(1-a_{\mathrm{H}}\right)(\phi-1)+1}\right] \frac{1-\varkappa_{1}}{1-\beta \delta_{1}} \beta \varkappa_{1} \widetilde{Y}_{H, t-1} .
\end{aligned}
$$

\footnotetext{
${ }^{45}$ In line with our earlier analysis, the extent to which the optimal policy response translates into a lower demand gap $\widetilde{\mathcal{D}}_{t}$ will depend on the degrees of openness and stickiness of import prices, i.e. on exchange rate pass-through.
} 
where

$$
\mathbf{B}=\left[1-\frac{1-\varkappa_{1}}{\varkappa_{2}-1} \frac{4 a_{\mathrm{H}}\left(1-a_{\mathrm{H}}\right)(\phi-1)}{\left[2 a_{\mathrm{H}}(\phi-1)+1\right]^{2}} \frac{4 a_{\mathrm{H}}\left(1-a_{\mathrm{H}}\right)(\phi-1)+1}{4 a_{\mathrm{H}}\left(1-a_{\mathrm{H}}\right)(\phi-1)+1+4 a_{\mathrm{H}}\left(1-a_{\mathrm{H}}\right) \frac{4 a_{\mathrm{H}}^{2}(\phi-1)^{2}}{\left[2 a_{\mathrm{H}}(\phi-1)+1\right]^{2}} \frac{(1-\beta)}{\beta\left(\varkappa_{2}-1\right)}}\right] \geq 0,
$$

The sign of capital flows is the same in the constrained-efficient allocation as in the natural rate allocation; however, capital flows are less volatile in the constrained-efficient allocation for $\phi>1$, more volatile for $1>\phi \geq 0$.

Proof. Constrained-efficient capital flows on impact are obtained in the above expression by setting $\widehat{\mathcal{B}}_{t-1}=\widetilde{Y}_{H, t-1}=0$, noting that $0<\mathbf{B}<1$ for $\phi>1$, while $\mathbf{B}>1$ for $1>\phi \geq 0$. As shown in the appendix, the lemma follows from the fact that the impact response of capital flows in the natural rate allocation is given by the same expression in the proposition but for setting $\mathbf{B}=1$

The allocation under the optimal policy in PCP economies is shown in Table 6, once again abstracting from contemporaneous shocks. ${ }^{46}$

Table 6: Constrained-efficient allocation under PCP with news shocks, for $\phi \geq 0$

$$
\begin{aligned}
& \widetilde{\mathcal{W}}_{t}=\mathbf{A} \cdot \beta \sum_{j=0}^{\infty} \beta^{j}\left[\begin{array}{c}
2 a_{\mathrm{H}}(\phi-1) E_{t}\left(\left(\widehat{Y}_{H, t+j+1}^{f b}-\widehat{Y}_{F, t+j+1}^{f b}\right)-\left(\widehat{Y}_{H, t+j}^{f b}-\widehat{Y}_{F, t+j}^{f b}\right)\right)+ \\
-\left(2 a_{\mathrm{H}}(\phi-1)+1\right) E_{t}\left(\left(\widehat{\zeta}_{C, t+1+j}-\widehat{\zeta}_{C, t+1+j}^{*}\right)-\left(\widehat{\zeta}_{C, t+j}-\widehat{\zeta}_{C, t+j}^{*}\right)\right)
\end{array}\right] \\
& \widetilde{Y}_{H, t}=\varkappa_{1} \widetilde{Y}_{H, t-1}-\left(1-a_{\mathrm{H}}\right)\left\{\begin{array}{c}
{\left[2 a_{\mathrm{H}}(\phi-1)+1\right] \frac{\left(\beta \varkappa_{2}-1\right)}{\beta \varkappa^{\prime}} \widetilde{\mathcal{W}}_{t}+} \\
2 a_{\mathrm{H}} \phi \frac{2 a_{\mathrm{H}}(\phi-1)}{2 a_{\mathrm{H}}(\phi-1)+1} \frac{1}{\beta \varkappa 2}\left(\widetilde{\mathcal{W}}_{t}-\widetilde{\mathcal{W}}_{t-1}\right)
\end{array}\right\} \\
& \theta \pi_{H, t}=\left(1-\varkappa_{1}\right) \widetilde{Y}_{H, t-1}+\left(1-a_{\mathrm{H}}\right) \frac{\left(\beta \varkappa_{2}-1\right)}{\beta \varkappa_{2}}\left\{\begin{array}{c}
{\left[2 a_{\mathrm{H}}(\phi-1)+1\right] \widetilde{\mathcal{W}}_{t}+} \\
-2 a_{\mathrm{H}} \phi \frac{2 a_{\mathrm{H}}(\phi-1)}{2 a_{\mathrm{H}}(\phi-1)+1}\left(\widetilde{\mathcal{W}}_{t}-\widetilde{\mathcal{W}}_{t-1}\right)
\end{array}\right\} \\
& \widetilde{\mathcal{Q}}_{t}=\left(2 a_{\mathrm{H}}-1\right) \frac{2 \widetilde{Y}_{H, t}-\left(2 a_{\mathrm{H}}-1\right) \widetilde{\mathcal{W}}_{t}}{4 a_{\mathrm{H}}\left(1-a_{\mathrm{H}}\right)(\phi-1)+1}
\end{aligned}
$$

The following Proposition 10 (which is the counterpart of Proposition 8) states the properties of this constrained efficient allocation, showing that the results for the $\mathrm{CO}$ economy generalize to any value of the the trade elasticity, but for the output gap and misalignment. For these two variables to behave the same way as in the CO economy, a sufficient condition is that the trade elasticity be greater or equal to unity. The proposition also stresses a key new finding. Namely, the optimal policy now stabilizes the wealth gap, making it less volatile than under strict price stability.

Proposition 10. For $\sigma=1, \eta=0$, and $\phi \geq 0$, under PCP, in response to news shocks generating inefficient capital flows, the GDP deflator is more volatile under the optimal policy than in a regime pursuing strict inflation stability, while the wealth gap is less volatile. Misalignment and the output gap are less volatile on impact for $\phi \geq 1$.

Proof: The result from inflation follows from Table 6 . The rest of the proof proceeds in

${ }^{46}$ The coefficient $\mathbf{A}$ multiplying the shock term in the expression for $\widetilde{\mathcal{W}}_{t}$ is given by

$$
\mathbf{A}=\frac{\left[2 a_{\mathrm{H}}(\phi-1)+1\right]^{-1}}{4 a_{\mathrm{H}}\left(1-a_{\mathrm{H}}\right)(\phi-1)+1+4 a_{\mathrm{H}}\left(1-a_{\mathrm{H}}\right) \phi \frac{4 a_{\mathrm{H}}^{2}(\phi-1)^{2}}{\left[2 a_{\mathrm{H}}(\phi-1)+1\right]^{2}} \frac{(1-\beta)}{\beta \varkappa_{2}\left(1-\beta \varkappa_{1}\right)}} ;
$$

its sign depends on whether $\phi$ is above or below the threshold (36). 
two steps. First, we refer to the appendix for a proof that $\widetilde{\mathcal{W}}_{t}$ is always less volatile than $\widetilde{\mathcal{W}}_{t}^{n a}$. Second, given this fact, the result for the output gap follows by setting $\widetilde{Y}_{H, t-1}=\widetilde{\mathcal{W}}_{t-1}=0$ in Table 6, and comparing the impact response of the constrained-efficient output gap, $\widetilde{Y}_{H, t_{0}}$, with $\tilde{Y}_{H, t_{0}}^{n a}$ :

$$
\begin{aligned}
& \widetilde{Y}_{H, t_{0}}=-\left(1-a_{\mathrm{H}}\right)\left[2 a_{\mathrm{H}}(\phi-1)+1\right]\left\{1-\frac{4 a_{\mathrm{H}}\left(1-a_{\mathrm{H}}\right)(\phi-1)+1}{\left[2 a_{\mathrm{H}}(\phi-1)+1\right]^{2} \beta \varkappa_{2}}\right\} \widetilde{\mathcal{W}}_{t_{0}} \\
& \widetilde{Y}_{H, t_{0}}^{n a}=-\left(1-a_{\mathrm{H}}\right)\left[2 a_{\mathrm{H}}(\phi-1)+1\right] \widetilde{\mathcal{W}}_{t_{0}}^{n a},
\end{aligned}
$$

whereas the coefficient of $\widetilde{\mathcal{W}}_{t_{0}}$ in $\widetilde{Y}_{H, t_{0}}$ is smaller in absolute value that of $\widetilde{\mathcal{W}}_{t_{0}}^{n a}$ in $\widetilde{Y}_{H, t_{0}}^{n a}$ for any $\phi \geq 1$ (since the term $\left|1-\frac{4 a_{\mathrm{H}}\left(1-a_{\mathrm{H}}\right)(\phi-1)+1}{\left[2 a_{\mathrm{H}}(\phi-1)+1\right]^{2} \beta \varkappa 2}\right|<1$ for $\phi \geq 1$ ). The result for misalignment (the real exchange rate) follows from noting that its expression in Table 6 for the constrained-efficient allocation also holds in the natural allocation, and using the fact that $\widetilde{\mathcal{W}}_{t_{0}}$ is always less volatile than $\widetilde{\mathcal{W}}_{t_{0}}^{n a}$, while $\widetilde{Y}_{H, t_{0}}$ is less volatile than $\widetilde{Y}_{H, t_{0}}^{n a}$ for $\phi \geq 1$

Remarkably, under PCP, the elasticity threshold determining the sign of $\widetilde{\mathcal{W}}_{t}$ conditional on a capital inflow $\widetilde{\mathcal{B}}_{t}<0$ is the same as the one derived for the natural rate allocation (36), and thus invariant to the type of shocks (whether anticipated taste and productivity shocks). ${ }^{47}$ In line with the LCP case, for elasticities above the threshold (36), the optimal monetary response to a capital inflow is similar to the one derived in the CO economy. Capital inflows associated with over-valuation and $\widetilde{\mathcal{W}}_{t}>0$ call for easier monetary policy at Home. A graphical illustration of this case is provided in the first column of Figure 2, under the same parameterization of the LCP economy and the same positive value of $\widetilde{\mathcal{W}}_{t}$. The impulse responses in the PCP economy are drawn as dashed red line. In line with Table 6, the response of inflation to capital inflows is positive. Note that, even if the optimal stance is expansionary and stokes inflationary pressures, misalignment and the welfare-relevant output gap are more negative and volatile than in the $\mathrm{CO}$ economy - reflecting higher expenditure switching effects of exchange rate movements due to a higher elasticity.

Nevertheless, relative to the natural rate allocation, the Home relative expansionary stance always contains exchange rate overvaluation and may even result in undervaluation, when $\phi$ is below one and sufficiently close to the threshold (36). ${ }^{48}$

\footnotetext{
${ }^{47}$ This is so because, in the expression for $\widehat{\mathcal{B}}_{t}$, first, the coefficient $\mathbf{B}$ is always positive for any value of $\phi$, and multiplied by the negative term $-\frac{\left(1-a_{\mathrm{H}}\right)}{4 a_{\mathrm{H}}\left(1-a_{\mathrm{H}}\right)(\phi-1)+1}$. Second, the sign of the coefficient $\mathbf{A}$ depends instead on whether $\phi$ is above or below the threshold (36).

${ }^{48}$ Recall that under the natural allocation misalignment is given by $\widetilde{\mathcal{Q}}_{t}^{n a}=-\left(2 a_{\mathrm{H}}-1\right) \widetilde{\mathcal{W}}_{t}^{n a}$ and has always the opposite sign of $\widetilde{\mathcal{W}}_{t}^{n a}$. The result in the text can be appreciated by rewriting the impact response of the real
} exchange rate gap under the optimal policy as follows:

$$
\widetilde{\mathcal{Q}}_{t_{0}}=-\left(2 a_{\mathrm{H}}-1\right)\left\{1-\frac{2\left(1-a_{\mathrm{H}}\right)}{\beta \varkappa_{2}\left[2 a_{\mathrm{H}}(\phi-1)+1\right]}\right\} \widetilde{\mathcal{W}}_{t_{0}}
$$

the term in curly brackets is positive, hence the real exchange rate is underappreciated, if

$$
\phi \geq \frac{1+\left(2 a_{\mathrm{H}}-1\right)\left(\beta \varkappa_{2}-1\right)}{\beta \varkappa_{2}},
$$

an expression that is lower than 1, but larger than the threshold (36). 


\subsection{Optimal stabilization with inefficient borrowing and currency underval- uation}

We conclude our analysis of monetary policy discussing the LCP and the PCP economy together, when, in response to news shocks, capital inflows are associated with inefficiently low domestic demand and real exchange rate undervaluation, $\widehat{\mathcal{B}}_{t}<0$ and $\widetilde{\mathcal{W}}_{t}<0$-which is generally the case for a sufficiently low trade elasticity. Drawing on Tables 3 and 6 above, the sign of the optimal policy response to excessive inflows is always a monetary expansion, irrespective of the degree of pass-through. As Home monetary authorities focus on supporting demand, misalignment is exacerbated and the real exchange rate is more volatile than under both strict CPI and GDP deflator stability.

We contrast the LCP and PCP economies in the right column in Figure 2. In this column we keep the absolute value of $\widetilde{\mathcal{W}}_{t}$ associated to a capital inflow the same as in the first column, but flip its sign to negative, also setting $\phi=0.3 .{ }^{49}$ In the LCP economy, the optimal monetary stance switches sign and is no longer contractionary, bringing the Home output gap close to zero (for a lower $\phi$, the output gap could even turn positive, as follows from setting $\phi \rightarrow 0$ in (39)). Relative to strict CPI targeting, a stronger Home aggregate demand and economic activity will correspond to a more depreciated, hence more volatile, real exchange rate.

In the PCP economy, the optimal stance does not change sign for values of $\phi$ below (36), despite $\widetilde{\mathcal{W}}_{t}>0$. However, as shown in Figure 2, the monetary stimulus is now substantial, causing massive exchange rate overshooting and a sizeable positive output gap. Relative to the natural rate, the volatility of these variables is much larger. ${ }^{50}$

\section{Conclusions}

Much research has been devoted to reconsider the set of policy tools and measures that can be activated to insulate national economies from the ebb and flows of cross-border capital flows. In this paper, we have taken the perspective of monetary policy decision making, and analyzed what monetary instruments can deliver when additional tools are not readily available and/or are of limited effectiveness. Our main question is how monetary policy could optimally respond to inefficient capital flows, impacting on domestic macroeconomic dynamic and welfare, by optimally trading off domestic and external objectives.

Our study provides key analytical insights into the efficient resolution of this trade-off. When international capital markets are imperfect (so that capital flows are associated with currency misalignment), the design of optimal monetary rules hinges on recognizing the direct and indirect relevance of exchange rates for domestic stabilization and welfare. The workhorse new Keynesian model delivers sharp and insightful prescriptions in this respect. In the common

\footnotetext{
${ }^{49}$ In the PCP economy, under the chosen parameterization, this value is below the relevant threshold fall all shocks. In the LCP economy, we assume conditons on anticipated productivity shocks that result in $\widehat{\mathcal{B}}_{t}<0$ and $\widetilde{\mathcal{W}}_{t}<0$ - see the appendix.

${ }^{50}$ Under the optimal policy, the impact response of inflation, shown below:

$$
\theta \pi_{H, t}=\left(1-a_{\mathrm{H}}\right) \frac{\beta \varkappa_{2}-1}{\beta \varkappa_{2}}\left[4 a_{\mathrm{H}}\left(1-a_{\mathrm{H}}\right)(\phi-1)+1\right] \frac{\widetilde{\mathcal{W}}_{t}}{2 a_{\mathrm{H}}(\phi-1)+1} \geq 0
$$

is invariably positive independently of the value of $\phi$. To wit: (41), the last term on the right-hand side, $\left[2 a_{\mathrm{H}}(\phi-1)+1\right]^{-1} \widetilde{\mathcal{W}}_{t}$, is always positive for $\widehat{\mathcal{B}}_{t}<0$, independently of whether $\widetilde{\mathcal{W}}_{t}$ is positive or negative.
} 
case in which inefficient capital inflows are associated with currency overappreciation and a demand boom, the optimal monetary stance crucially depends on ERPT. It is contractionary in economies in which incomplete ERPT mutes the effects of exchange rates on the output gap, to curb the demand boom; conversely, it is expansionary in economies in which ERPT is complete, leaning against overappreciation. As a result, relative to the benchmark of strict price stability, the exchange rate is more volatile under LCP, and less volatile under PCP. In cases in which inefficient capital inflows result in a fall in relative domestic demand and undervaluation of the exchange rate, the optimal policy is instead the same irrespective of exchange rate pass through. Under the optimal policy, the response is expansionary in support of domestic economic activity. Misalignment is exacerbated and the real exchange rate is more volatile than under strict price stability for both LCP and PCP.

Moving forward, there are a number of promising directions of research. The interplay of domestic and cross-border financial frictions may strengthen the case for domestic stabilization at the cost of higher exchange rate volatility under LCP. This would possibly be the case if a share of the residents in each country is excluded from financial markets, and thus operates under financial autarky. ${ }^{51}$ By the same token, a non-zero stock of foreign assets and liabilities would introduce valuation effects due to misalignment, on top and above the income effects of exchange rate movements stressed by our analysis (see Benigno [2007]).

Strategic interactions among policymakers are another key issue. Inefficient capital flows have strong redistributive effects across borders. Cooperative policies attempt to redress these effects: in our analysis, when the optimal monetary policy at Home is either a contraction or an expansion, the Foreign monetary stance has the opposite sign. Without cooperation, however, these redistributive effects of capital inflows inherently create room for conflicts and strategic behavior.

Finally, while in this paper we focus on the benchmark cases of PCP and LCP, the evidence on the importance of pricing in vehicle (or dominant) currencies strongly motivates further work exploring the case of asymmetric pass-through, or DCP (see Gopinath [2016] and Casas et al. [2016]). An important question is which direction monetary policy will take in the country which issues the dominant currency, when facing a capital inflow with currency overvaluation or undervaluation. ${ }^{52}$

\section{References}

[1] Acharya, Sushant and Julien Bengui [2016]. "Liquidity traps, capital flows." Staff Report, Federal Reserve Bank of New York, No. 765.

\footnotetext{
${ }^{51}$ In previous work [Corsetti et al. 2010], we have worked out the loss function and the optimal policy under financial autarky and complete markets. These results provide useful insight on the optimal policy in a two-agent specification of our model (whereas a share of the population trades a complete set of Arrow-Debreu securities international, while a share of the population operates under financial autarky). The optimal policy takes the form of weighted average of the optimal policies under complete markets and financial autarky.

${ }^{52}$ In ongoing work, we find that in a CO economy with DCP, in response to a capital inflow with overappreciation, the dominant currency issuer implements a monetary expansion. Similarly to PCP, it curbs exchange rate volatility at the expense of inflation stabilization.
} 
[2] Backus, David K., and Gregor W. Smith, [1993]. "Consumption and Real Exchange Rates in Dynamic Economies with Non-traded Goods," Journal of International Economics 35, pp. 297-316.

[3] Barro, Robert J., and Robert G. King, [1984]. "Time-Separable Preferences and Intertemporal-Substitution Models of Business Cycles." Quarterly Journal of Economics, 99 (4), pp. 817- 839.

[4] Beaudry, Paul and Franck Portier, [2006]. "Stock Prices, News, and Economic Fluctuations," American Economic Review, 96, pp. 1293-1307.

[5] Beaudry, Paul, Martial Dupaigne, and Franck Portier [2008]. "The International Transmission of News Shocks", manuscript.

[6] Benigno, Pierpaolo [2009]. "Price Stability with Imperfect Financial Integration", Journal of Money, Credit and Banking, 41, pp. 121-149.

[7] Benigno, Gianluca and Pierpaolo Benigno [2003]. "Price Stability in Open Economies," Review of Economic Studies 70, pp. 743-764.

[8] Benigno, Gianluca, Huigang Chen, Christopher Otrok, Alessandro Rebucci and Eric Young [2010]. "Revisiting Overborrowing and its Policy Implications,"CEPR DP. No. 7872.

[9] Bernanke, Ben [2005], "The global saving glut and the U.S. current account deficit" Speech 77, Board of Governors of the Federal Reserve System (U.S.).

[10] Bianchi, Javier [2011]. "Overborrowing and Systemic Externalities in the Business Cycle," American Economic Review 101 (7), pp. 3400-3426.

[11] Bianchi, Javier and Enrique Mendoza [2010]. "Overborrowing, Financial Crises and Macroprudential Taxes," NBER Working Paper 16091.

[12] Brunnermeier, M.K, and Y. Sannikov [2015]. "International Credit Flows and Pecuniary Externalities". American Economic Journal: Macroeconomics 71, pp. 297-338.

[13] Cavallino Paolo [2019], "Capital Flows and Foreign Exchange Intervention." Forthcoming American Economic Journal: Macroeconomics, Vol. 11, pp. 127-70.

[14] Clarida, R., Galí J. and Gertler, M. [2002], "A Simple Framework for International Policy Analysis." Journal of Monetary Economics 49, pp. 879-904.

[15] Cole, Harold L., and Maurice Obstfeld [1991]. "Commodity Trade and International Risk Sharing: How Much Do Financial Markets Matter?" Journal of Monetary Economics 28, pp. 3-24.

[16] Corsetti, Giancarlo and Paolo Pesenti [2005]. "International Dimensions of Optimal Monetary Policy", Journal of Monetary Economics 52, pp. 281-305.

[17] Corsetti Giancarlo, Luca Dedola and Sylvain Leduc [2008a]. "International Risk-Sharing and the Transmission of Productivity Shocks," Review of Economic Studies 75, pp. 443-473. 
[18] Corsetti Giancarlo, Luca Dedola and Sylvain Leduc [2008b]. "High exchange rate volatility and low pass-through," Journal of Monetary Economics 55, pp. 1113-1128.

[19] Corsetti Giancarlo, Luca Dedola and Sylvain Leduc [2010]. "Optimal Monetary Policy in Open Economies," in Benjamin Friedman and Michael Woodford, Handbook of Monetary Economics, Vol. 3B, pp. 861-934.

[20] Cúrdia Vasco and Michael Woodford [2016]. "Credit Frictions and Optimal Monetary Policy," Journal of Monetary Economics, 84 pp. 30-65.

[21] Dávila Eduardo and Anton Korinek [2018]. "Pecuniary Externalities in Economies with Financial Frictions." Review of Economic Studies 85(1): 352-395.

[22] De Paoli, Bianca [2009]. "Monetary Policy under Alternative Asset Market Structures: The Case of a Small Open Economy," Journal of Money, Credit and Banking 41(7), pp. 1301-1330.

[23] Devereux, Michael B. [2004]. "Should the exchange rate be a shock absorber?", Journal of International Economics 62, pp. 359-377.

[24] Devereux, Michael B. and Charles Engel [2003]. "Monetary policy in the open economy revisited: Price setting and exchange-rate flexibility", Review of Economic Studies 70, pp.765-783.

[25] Devereux, Michael B. and Charles Engel [2007]. "Expectations, Monetary Policy, and the Misalignment of Traded Goods Prices", NBER International Seminar on Macroeconomics.

[26] Devereux, Michael B. and Alan Sutherland [2008]. "Financial Globalization and Monetary Policy." Journal of Monetary Economics 55, pp.1363-1375.

[27] Devereux, Michael B. and Changhua Yu [2016], "Monetary and Exchange Rate Policy with Endogenous Financial Constraints," mimeo, University of British Columbia.

[28] Engel, Charles [2011]. "Currency Misalignments and Optimal Monetary Policy: A Reexamination," American Economic Review 101, pp. 2796-2822.

[29] Fanelli, Sebastian [2019]. "Monetary Policy, Capital Controls and International Portfolios", manuscript, CEMFI.

[30] Farhi, Emmanuel, and Ivan Werning. 2016. "A Theory of Macroprudential Policies in the Presence of Nominal Rigidities." Econometrica 84 (5): 1645-1704.

[31] Farhi, Emanuel and Ivan Werning [2014], "Dilemma not Trilemma? Capital Controls and Exchange Rates with Volatile Capital Flows." IMF Economic Review (Special Volume in Honor of Stanley Fischer) 62. pp. 569-605.

[32] Ferrero, Andrea, Mark Gertler and Lars E.O. Svensson [2009]. "Current Account Dynamics and Monetary Policy," in J. Galí and M. Gertler (Editors), International Dimensions of Monetary Policy, pp 199-250. 
[33] Gabaix, Xavier and Matteo Maggiori [2015]. "International liquidity and exchange rate dynamics", Quarterly Journal of Economics, 130 (3), pp. 1369-1420.

[34] Galí, Jordi and Tommaso Monacelli [2005]. "Monetary Policy and Exchange Rate Volatility in a Small Open Economy", Review of Economic Studies 72, pp. 707-734.

[35] Geanakoplos, John and Herakles Polemarchakis [1986]. "Existence, regularity, and constrained suboptimality of competititve allocations when the asset market is incomplete," in: Essays in Honor of Kenneth J. Arrow; Uncertainty, Information and Communication, Vol. 3; Heller, W. P.; Starr, R. M.; Starrett, D. A., Eds.; Cambridge University press: Cambridge, pp. 65-96.

[36] Gopinath Gita [2016] "The International Price System", Jackson Hole Symposium Proceedings.

[37] Gravelle, Hugh, and Ray Rees [1992]. Microeconomics, London: Longman.

[38] Gourinchas, Pierre-Olivier and Rey, Helene, 2014. "External Adjustment, Global Imbalances, Valuation Effects," in Gopinath, G. \& Helpman, . \& Rogoff, K. (ed.), Handbook of International Economics, Elsevier.

[39] Jeanne, Olivier and Anton Korinek [2010]. "Excessive Volatility in Capital Flows: A Pigouvian Taxation Approach," American Economic Review, vol. 100(2), pp. 403-07.

[40] Keynes, J. M. [1929a]. "The German Transfer Problem," The Economic Journal, 39, pp. $1-7$.

[41] Keynes, J. M. [1929b] "The Reparations Problem: A Discussion. II. A Rejoinder," The Economic Journal, 39, pp. 179-182.

[42] Keynes, J. M. [1929c] "Mr. Keynes' Views on the Transfer Problem. III. A Reply," The Economic Journal, 39, pp. 404-408.

[43] Kollmann, Robert [2002]. "Monetary policy rules in the open economy: effects on welfare and business cycles", Journal of Monetary Economics 49, pp. 989-1015.

[44] Lorenzoni, Guido [2008]. "Inefficient Credit Booms," Review of Economic Studies, 75(3), pp. 809-833.

[45] Obstfeld, Maurice, and Kenneth Rogoff [1995]. "Exchange Rate Dynamics Redux," Journal of Political Economy, 103(3), pp. 624-60.

[46] Obstfeld, Maurice [2019]. "Global dimensions of US monetary policy," NBER Working Paper 26039.

[47] Obstfeld, Maurice, and Kenneth Rogoff [2001]. "The six major puzzles of international macroeconomics: Is there a common cause?" NBER Macroeconomics Annual.

[48] Obstfeld, Maurice, and Kenneth Rogoff [2003]. "Global Implications of Self-Oriented National Monetary Rules," The Quarterly Journal of Economics, 117(2) pp. 503-535. 
[49] Obstfeld, Maurice, and Kenneth Rogoff [2005]. "Global current account imbalances and exchange rate adjustments," Brookings Papers on Economic Activity 1, pp. 67-123.

[50] Obstfeld, Maurice, and Kenneth Rogoff [2010]. "Global Imbalances and the Financial Crisis: Products of Common Causes," Asia and the Global Financial Crisis, Asia Economic Policy Conference, Federal Reserve Bank of San Francisco, pp. 131-172.

[51] Ohlin, B. [1929a]. "The Reparations Problem: A Discussion; Transfer Difficulties, Real and Imagined," The Economic Journal, 39, pp. 172-183.

[52] Ohlin, B. [1929b]. "Mr. Keynes' Views on the Transfer Problem. II. A Rejoinder from Professor Ohlin," The Economic Journal, 39, pp. 400-404.

[53] Rabitsch, Katrin [2012], "The Role of Financial Market Structure and the Trade Elasticity for Monetary Policy in Open Economies", Journal of Money, Credit and Banking, 44(4), pp. 1538-4616.

[54] Rey Hélène [2013], "Dilemma not Trilemma: The Global Financial Cycle and Monetary Policy Independence", Jackson Hole.

[55] Senay Ozge and Alan Sutherland [2016], "Optimal Monetary Pollicy, Exchange Rate Misalignments and Incomplete Financial Markets," Journal of International Economics, vol. 117, pp. 196-208

[56] Schmitt-Grohe Stephanie and Martin Uribe [2003]. "Closing small open economies." Journal of International Economics, vol. 61, pp. 163-185.

[57] Schmitt-Grohe Stephanie and Martin Uribe [2012]. "What's News in Business Cycles." Econometrica (80):2733-2764.

[58] Tille, Cédric [2005]. "The welfare effect of international asset market integration under nominal rigidities," Journal of International Economics, Volume 65 (1), pp. 221-247.

[59] Woodford, Michael [2009]. "Globalization and Monetary Control" in Jordi Galí and Mark Gertler (Editors), International Dimensions of Monetary Policy. pp. 13-88.

[60] Woodford, Michael [2010]. "Optimal Monetary Stabilization Policy," in Benjamin Friedman and Michael Woodford, Handbook of Monetary Economics, Vol. 3B, pp. 723-828. 


\section{Figure 1}
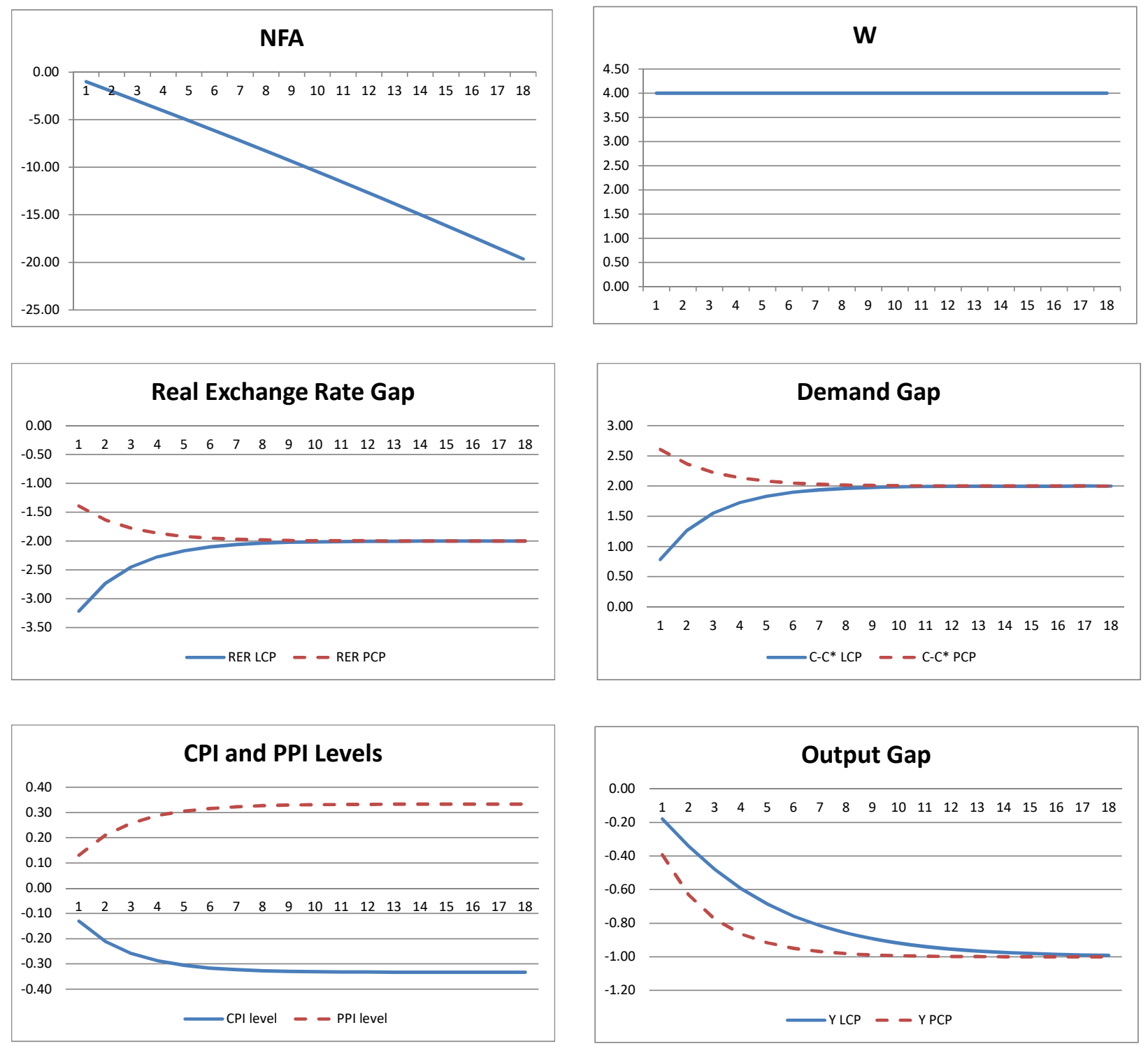

The figure is drawn for anticipated taste shocks that materialize after period 20 (not shown in the graphs). Parameter values are as follows: $\eta=0, \phi=\sigma=1, a H=.75, \beta=.99, \alpha=.75, \theta=3$. 
Figure 2

Capital Inflows with positive wealth gap
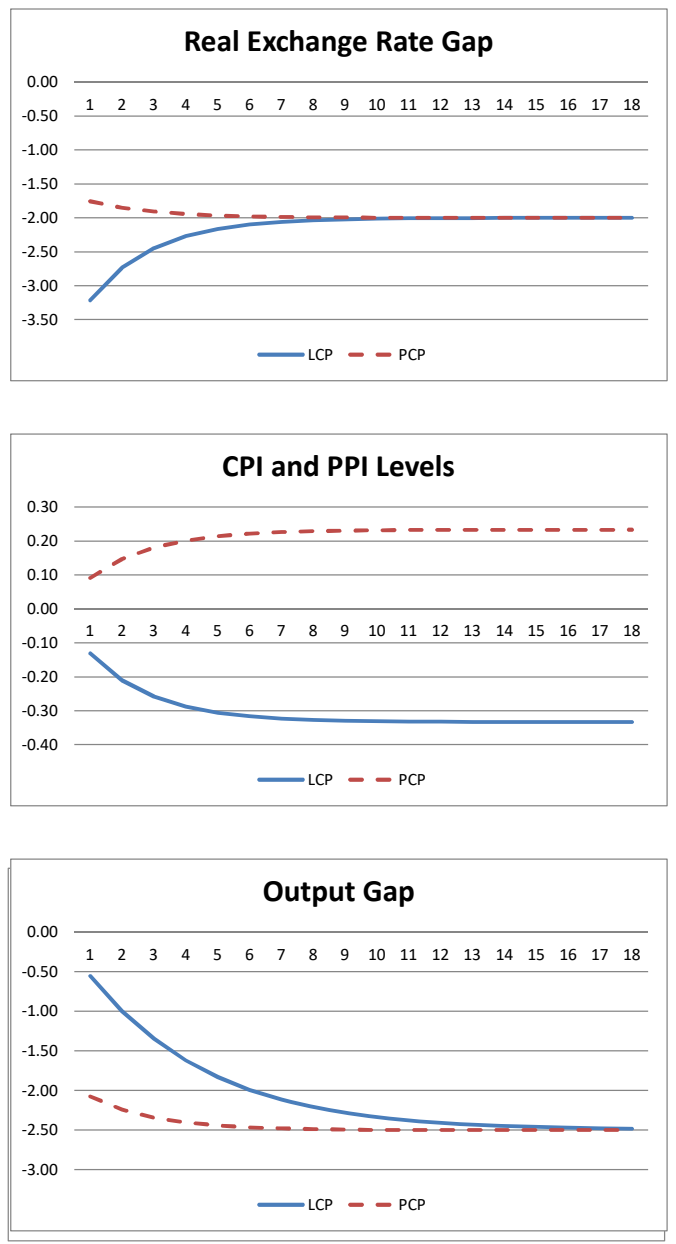

Capital Inflows with negative wealth gap
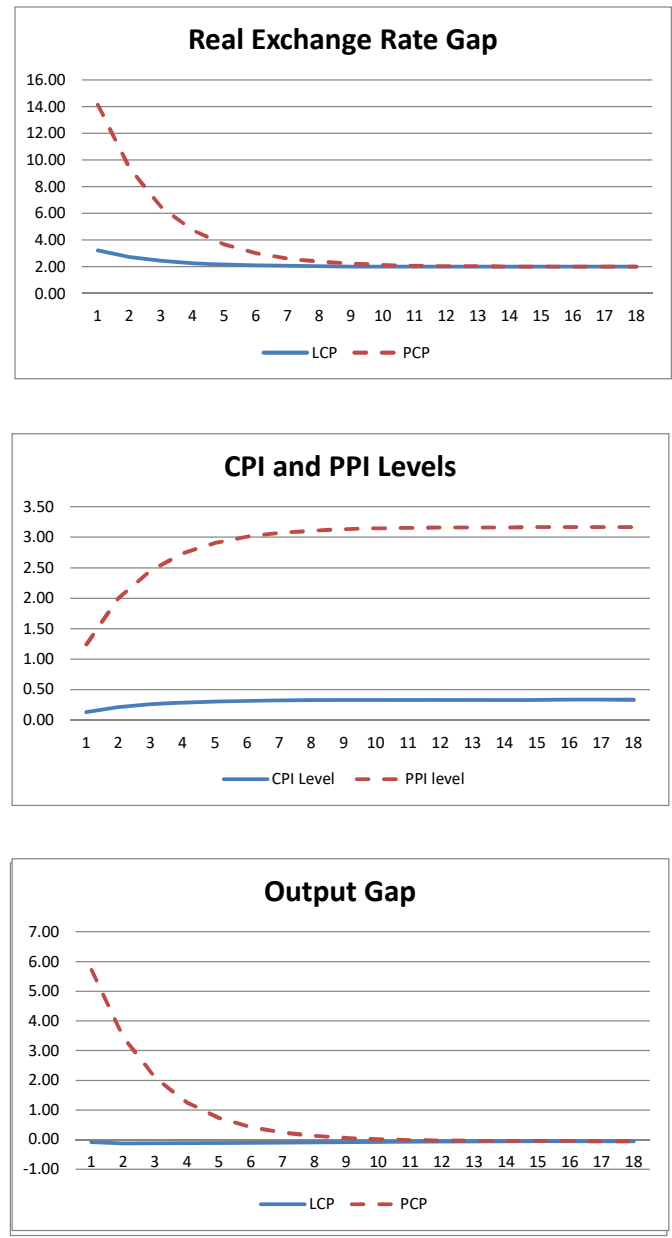

The figure is drawn for anticipated productivity shocks that materialize after period 20 (not shown in the graphs) Parameter values are as follows: $\eta=0, \sigma=1, a H=.75, \beta=.99, \alpha=.75, \theta=3$ and $\phi=2$ (left column) or $\phi=.3$ (right column) 